NBER WORKING PAPER SERIES

\title{
OPTIMAL TAXATION WHEN CONSUMERS HAVE ENDOGENOUS BENCHMARK LEVELS OF CONSUMPTION
}

\author{
Andrew B. Abel \\ Working Paper 10099 \\ http://www.nber.org/papers/w10099 \\ NATIONAL BUREAU OF ECONOMIC RESEARCH \\ 1050 Massachusetts Avenue \\ Cambridge, MA 02138 \\ November 2003
}

I thank Bill Dupor, Joao Gomes, and Skander van den Heuvel for helpful discussion, Martin Gervais and Carlos Garriga for helpful correspondence, the Penn Macro Lunch Group, seminars at Carnegie-Mellon University, the University of Rochester, and the University of Washington, and two referees and the editor for helpful comments. The views expressed herein are those of the authors and not necessarily those of the National Bureau of Economic Research.

(C)2003 by Andrew B. Abel. All rights reserved. Short sections of text, not to exceed two paragraphs, may be quoted without explicit permission provided that full credit, including (C) notice, is given to the source. 
Optimal Taxation When Consumers Have Endogenous Benchmark Levels of Consumption Andrew B. Abel

NBER Working Paper No. 10099

November 2003

JEL No. E21, H31

\section{$\underline{\text { ABSTRACT }}$}

I examine optimal taxes in an overlapping generations economy in which each consumer's utility depends on consumption relative to a weighted average of consumption by others (the benchmark level of consumption) as well as on the level of the consumer's own consumption. The socially optimal balanced growth path is characterized by the Modified Golden Rule and by a condition on the intergenerational allocation of consumption in each period. A competitive economy can be induced to attain the social optimum by a lump-sum pay-as-you-go social security system and a tax on capital income.

Andrew B. Abel

Department of Finance, SH-DH 2315

The Wharton School

University of Pennsylvania

3620 Locust Walk

Philadelphia, PA 19104-6367

and NBER

abel@wharton.upenn.edu 
Conventional economic theory assumes that the utility of a person or a family is independent of the consumption of others. Yet a visit to the parking lot of a suburban shopping mall may tempt an economist to question this independence. Has the proliferation of sport utility vehicles owned by nonadventurous people in moderate climates resulted from factors that are the focus of traditional economic analysis, such as increased income or wealth, superior hedonic traits, or sharp reductions in the prices of these vehicles or their complementary goods, such as gasoline? Pending the econometric resolution of this question, I will pursue the temptation to question the independence of a person's utility from the consumption of others. A half century ago, Duesenberry (1949) questioned the apparent preference for Buicks over Chevrolets and developed a theory of consumption and saving based on the assumption that a person's utility is a function of that person's consumption relative to the average level of consumption in society. ${ }^{1}$

\footnotetext{
1 "It is well known that there are societies in which prestige is gained by the acquisition of some sort of good which is completely useless in fulfilling any need whatever. In spite of the complete uselessness of the things in question, their acquisition may be vital to the acquisition of prestige or maintenance of self-esteem. A great deal of effort may be expended in acquiring these useless items. In our society people may think that they expend effort to get a Buick instead of a Chevrolet because the Buick is more comfortable
} 
I will assume that consumers use an endogenous benchmark level of consumption to evaluate their utility. I will specify the benchmark level of consumption to be a weighted geometric average of the contemporaneous consumption of all consumers in the economy. In addition to a person's own consumption, I will include in the utility function a person's own consumption relative to the benchmark level of consumption. Abel $(1990,1999)$ and Campbell and Cochrane (1999) have shown that including a benchmark level of consumption in the utility function can help account for various puzzling empirical moments of asset returns. Here my focus is on the allocation of consumption across generations and across time and on aggregate capital accumulation. $^{2}$ I will modify the Diamond (1965) overlapping generations or goes faster. But this does not in the least prove that part of the basis for the purchase is not the maintenance of self-esteem." (Duesenberry, 1949, p. 29)

${ }^{2}$ Dupor and Liu (2002) develop a taxonomy for various features of consumption externalities. If utility is $u(c, b)$, where $c$ is the individual's own consumption and $b$ is a benchmark that equals the average level of consumption by others, they define jealousy as $\partial u / \partial b<0$ and keeping up with the Joneses as $\partial^{2} u / \partial c \partial b>0$. They show that keeping up with the Joneses is important for asset pricing considerations and jealousy is important for consumption allocations. The utility function I use in this paper displays jealousy. It also displays keeping up with the Joneses for the case in which the curvature parameter $\alpha$, introduced in equation (11), is greater than one. 
model to include a benchmark level of consumption in the utility function of individuals. The introduction of a benchmark level of consumption leads to a straightforward modification of the equilibrium balanced growth path in a competitive economy. More interesting is the modification of the balanced growth path that maximizes a social welfare function that assigns geometrically declining weights to the utility of subsequent generations. The socially optimal balanced growth path is characterized by the same Modified Golden Rule as in standard neoclassical growth models. However, the concern for consumption relative to the benchmark level of consumption introduces an optimality condition on the allocation of consumption across generations that are simultaneously alive.

After deriving the competitive balanced growth path and the socially optimal balanced growth path, the next step is to characterize a set of tax and transfer policies that will induce the competitive economy to attain the social optimum. In a standard neoclassical growth model without a benchmark level of consumption, a balanced-budget lump-sum intergenerational tax/transfer scheme, which could be interpreted as pay-as-you-go social security, can be used to achieve the appropriate level of saving for the economy to attain the Modified Golden Rule. However, an additional fiscal tool is 
needed to attain the socially optimal balanced growth path when, in addition to the level of their own consumption, consumers care about their consumption relative to the benchmark level of consumption. This appearance of the benchmark level of consumption in the utility function introduces an externality in consumption, and, not surprisingly, the attainment of the social optimum requires a distortionary tax. ${ }^{3}$ In particular, a capital income tax or subsidy, offset by lump-sum rebates or taxes, and accompanied by the appropriate social security system will induce the competitive economy to attain the social optimum.

At some level, the use of a lump-sum intergenerational tax/transfer system to attain the Modified Golden Rule and the use of distortionary taxes on capital income to correct a consumption externality are not surprising. Yet, in principle, the signs of these taxes could be positive or negative. Specifically, the optimal intergenerational tax/transfer system could involve transfers from young consumers, who are working, to old consumers who are retired, as in a social security system, or the transfers could be in the opposite direction, from old to young. Also, the optimal tax rate on capital income

\footnotetext{
${ }^{3}$ Duesenberry (1949), Boskin and Sheshinski (1978), Ljungqvist and Uhlig (2000), and de la Croix and Michel (1999) have derived optimal distortionary taxes in the presence of various sorts of consumption externalities.
} 
could be positive, negative, or zero. I address these potential ambiguities by deriving conditions on exogenous parameters that determine the direction of the transfers in the optimal social security system and the sign of the optimal tax rate on capital income. In the special, but perhaps focal, case in which benchmarks are equally-weighted geometric averages of the contemporaneous consumption of all consumers, I derive a surprising result: if the social planner is more patient than individuals, the optimal tax rate on capital income is positive. This result is surprising because an increase in the social planner's patience would increase the optimal capital-labor ratio, and one might be tempted to think that the social planner would foster capital accumulation by subsidizing capital. But as I show in Section 5, and summarize intuitively in the concluding remarks in Section 6, the greater patience of the social planner leads the social planner to favor later, i.e., younger, generations. The social planner can tilt a given amount of aggregate consumption in any period toward the younger generation alive in the period by taxing capital income at a positive rate. In addition to analytic results about the signs of the optimal taxes, I present illustrative calculations to demonstrate that, in plausible cases, the optimal lump-sum intergenerational (social security) transfers can be from young to old and that the optimal tax rate on 
capital income can be positive.

I use a standard neoclassical production function, which I present in Section 1. Then in Section 2 I define the benchmark level of consumption and incorporate it into the utility function of an individual consumer. Using the utility function with benchmark levels of consumption, I solve the optimal consumption decision of a young consumer and characterize the equilibrium balanced growth path in a competitive economy in Section 3. I specify the objective function of the social planner in Section 4 and characterize the socially optimal balanced growth path. This characterization includes the standard Modified Golden Rule and a condition that determines the optimal intergenerational allocation of consumption in each period. In Section 5, I derive and characterize the optimal tax and transfer policies that induce a competitive economy to attain the socially optimal balanced growth path. Concluding remarks are presented in Section 6. The appendixes contain derivations that would be distracting if presented in the text. 


\section{The Production Function}

Consider a closed economy with overlapping generations of consumers who live for two periods. Each generation consists of a continuum of identical consumers. Let $N_{t}$ be the measure of the consumers born at the beginning of period $t$, and let $G_{N} \equiv \frac{N_{t+1}}{N_{t}} \geq 1$ be the constant growth rate of the population. Consumers born at the beginning of period $t$ inelastically supply one unit of labor in period $t$ when they are young, and they supply no labor in period $t+1$ when they are old. ${ }^{4}$ Thus, the measure of workers in period $t$ is $N_{t}$.

The economy uses capital and labor to produce a homogenous good according to the production function $Y_{t}=F\left(K_{t}, A_{t} N_{t}\right)$ where $Y_{t}$ is aggregate output in period $t, K_{t}$ is the aggregate capital stock at the beginning of period $t$, and $A_{t}$ is an index of labor-augmenting productivity which grows at

\footnotetext{
${ }^{4}$ By specifying an inelastic supply of labor for young consumers and zero labor supply for old consumers, I am cutting off an important channel leading to non-zero optimal capital income taxes in Erosa and Gervais (2002) and Garriga (2001). I chose this inelastic specification of labor supply in order to focus on the impact of benchmark levels of consumption, which are absent in Erosa and Gervais (2002) and Garriga (2001). Ljungqvist and Uhlig (2000) derive optimal taxes (on labor income) with consumption externalites and endogenous labor supply, but their model does not include capital.
} 
a constant rate $G_{A} \equiv \frac{A_{t+1}}{A_{t}} \geq 1$. The production function $F($,$) is strictly$ increasing, concave, and linearly homogeneous in its two arguments $K_{t}$ and $A_{t} N_{t}$. It is convenient to write the production function in intensive form as

$$
Y_{t}=A_{t} N_{t} f\left(k_{t}\right)
$$

where $k_{t} \equiv \frac{K_{t}}{A_{t} N_{t}}$ is the effective capital-labor ratio, $f(0)=0, f^{\prime}\left(k_{t}\right)>0$, $f^{\prime}(0)=\infty, f^{\prime}(\infty)=0$, and $f^{\prime \prime}\left(k_{t}\right)<0$. Define $\varepsilon_{f}\left(k_{t}\right) \equiv \frac{k_{t} f^{\prime}\left(k_{t}\right)}{f\left(k_{t}\right)}$ as the elasticity of the production function $f\left(k_{t}\right)$ with respect to $k_{t}$. For positive finite values of $k_{t}, 0<\varepsilon_{f}<1$. The marginal product of capital is $f^{\prime}\left(k_{t}\right)$ and the marginal product of labor is $A_{t}\left[f\left(k_{t}\right)-k_{t} f^{\prime}\left(k_{t}\right)\right]$. I will assume that the labor market is competitive so that the wage income of a young consumer in period $t$ is

$$
w_{t}=A_{t}\left[f\left(k_{t}\right)-k_{t} f^{\prime}\left(k_{t}\right)\right] .
$$

Output produced during period $t$ has three uses. An amount $C_{t}$ is consumed by each of the $N_{t}$ young consumers during period $t$, an amount $X_{t}$ is consumed by each of the $N_{t-1}$ old consumers in period $t$, and the remaining output is devoted to creating the capital stock at the beginning of period $t+1, K_{t+1}=A_{t+1} N_{t+1} k_{t+1}$. Therefore, the aggregate resource 
constraint in period $t$ is

$$
A_{t} N_{t} f\left(k_{t}\right)=N_{t} C_{t}+N_{t-1} X_{t}+A_{t+1} N_{t+1} k_{t+1} .
$$

Using the assumptions that population and productivity grow at constant rates, $G_{N}$ and $G_{A}$, respectively, rewrite the aggregate resource constraint as

$$
f\left(k_{t}\right)=\frac{C_{t}}{A_{t}}+\frac{1}{G_{N}} \frac{X_{t}}{A_{t}}+G_{A} G_{N} k_{t+1} .
$$

Along a balanced growth path in this economy, the ratios $k_{t}, \frac{C_{t}}{A_{t}}$, and $\frac{X_{t}}{A_{t}}$ are all constant. Therefore, both $C_{t}$ and $X_{t}$ grow at the rate $G_{A}$, and the ratio $\frac{X_{t}}{C_{t}}$ is constant along a balanced growth path,

\section{The Utility Function with Benchmark Con-}

\section{sumption}

I will specify an individual consumer's utility function to depend in each period on the consumer's own consumption in that period and on a benchmark level of consumption that is a weighted geometric average of the contemporaneous consumption of other consumers. To specify the benchmark level of consumption more precisely, I will first introduce some notation for consumption. Let $c_{t}$ be the consumption in period $t$ of an individual young 
consumer (who was born at the beginning of period $t$ ), and let $x_{t}$ be the consumption in period $t$ of an individual old consumer (who was born at the beginning of period $t-1$ ). The variables $C_{t}$ and $X_{t}$ defined earlier are the per capita consumption levels of the young and old generations, respectively, and are not affected by the decisions of an individual consumer. An individual consumer born at the beginning of period $t$ chooses $c_{t}$ and $x_{t+1}$ and takes as given the values of $C_{t}, X_{t}, C_{t+1}$, and $X_{t+1}$. In equilibrium $c_{t}=C_{t}$ and $x_{t}=X_{t}$ because all consumers in a given generation are identical.

Now consider the benchmark levels of consumption for a consumer born at the beginning of period $t$. Let $\nu_{t}^{y}$ be the benchmark level of consumption for a young consumer in period $t$ and let $\nu_{t+1}^{o}$ be the benchmark level of consumption for an old consumer in period $t+1$. In each period the benchmark level of consumption is a weighted geometric average of the per capita consumption of the two living generations. Specifically,

$$
\nu_{t}^{y}=C_{t}^{\frac{G_{N}}{\theta_{y}+G_{N}}} X_{t}^{\frac{\theta_{y}}{\theta_{y}+G_{N}}}, \quad 0 \leq \theta_{y} \leq 1
$$

and

$$
\nu_{t+1}^{o}=C_{t+1}^{\frac{\theta_{o} G_{N}}{\theta_{o}}} X_{t+1}^{\frac{1}{\theta_{o} G_{N}+1}}, \quad 0 \leq \theta_{o} \leq 1
$$

The parameter $\theta_{y}$ in equation (5) is the weight of the consumption of a representative old consumer relative to the consumption of a representative 
young consumer in the specification of the benchmark for young consumers. The restriction that $\theta_{y} \leq 1$ implies that the benchmark for young consumers places at least as much weight on the consumption of a fellow young consumer as on the consumption of an old consumer. Similarly, the restriction $\theta_{o} \leq 1$ in equation (6) implies that the benchmark for old consumers places at least as much weight on the consumption a fellow old consumer as on the consumption of a young consumer.

To simplify notation, I rewrite the specification of the benchmarks in equations (5) and (6) as

$$
\nu_{t}^{y}=C_{t}^{1-\varepsilon_{y}} X_{t}^{\varepsilon_{y}}, \quad 0 \leq \varepsilon_{y} \equiv \frac{\theta_{y}}{\theta_{y}+G_{N}} \leq \frac{1}{1+G_{N}}
$$

and

$$
\nu_{t+1}^{o}=C_{t+1}^{\varepsilon_{o}} X_{t+1}^{1-\varepsilon_{o}}, \quad 0 \leq \varepsilon_{o} \equiv \frac{\theta_{o} G_{N}}{\theta_{o} G_{N}+1} \leq \frac{G_{N}}{1+G_{N}}
$$

The restrictions on $\varepsilon_{y}$ and $\varepsilon_{o}$ in equations (7) and (8) imply that $\varepsilon_{y}+$ $\varepsilon_{o} \leq 1$. If the benchmark for young consumers, $\nu_{t}^{y}$, is an equally-weighted geometric average of the consumption of all consumers alive in period $t$, then $\theta_{y}=1$ and $\varepsilon_{y}=\frac{1}{1+G_{N}}$. If the benchmark for old consumers, $\nu_{t+1}^{o}$, is an equally-weighted geometric average of the consumption of all consumers alive in period $t+1$, then $\theta_{o}=1$ and $\varepsilon_{o}=\frac{G_{N}}{1+G_{N}}$. Thus, when both benchmarks 
are equally-weighted geometric averages of consumption of all consumers, $\varepsilon_{o}+\varepsilon_{y}=1$ and $\varepsilon_{o}=\varepsilon_{y} G_{N}$.

It will be useful to define the (intratemporal) intergenerational consumption ratio $\sigma_{t} \equiv \frac{X_{t}}{C_{t}}$. With this definition, the benchmark levels of consumption in equations (7) and (8) can be written as

$$
\nu_{t}^{y}=C_{t} \sigma_{t}^{\varepsilon_{y}}
$$

and

$$
\nu_{t+1}^{o}=X_{t+1} \sigma_{t+1}^{-\varepsilon_{o}}=C_{t+1} \sigma_{t+1}^{1-\varepsilon_{o}}
$$

Now I will specify a utility function that incorporates benchmark levels of consumption. The utility of a consumer born at the beginning of period $t$ is

$$
U_{t}=\frac{1}{1-\alpha}\left(\frac{c_{t}}{\left(\nu_{t}^{y}\right)^{\eta}}\right)^{1-\alpha}+\beta \frac{1}{1-\alpha}\left(\frac{x_{t+1}}{\left(\nu_{t+1}^{o}\right)^{\eta}}\right)^{1-\alpha}
$$

where $\alpha>0, \beta>0$, and $0 \leq \eta<1$. The felicity in any given period can be viewed as an isoelastic function (with elasticity $1-\alpha$ ) of a geometric average of the consumer's own consumption and the consumer's own consumption relative to the benchmark level of consumption. For example, the consumer's felicity when young in period $t$ is an isoelastic function of $\frac{c_{t}}{\left(\nu_{t}^{y}\right)^{\eta}}$, which can be expressed as $c_{t}^{1-\eta}\left(\frac{c_{t}}{\nu_{t}^{y}}\right)^{\eta}$. The parameter $\eta$ measures the (geometric) weight 
of the ratio of the consumer's own consumption to the benchmark level of consumption. If $\eta=0$, this ratio does not enter the utility function, and utility is simply an isoelastic function of the consumer's own consumption, as in the conventional formulation of isoelastic utility. If $\eta$ were equal to one, then the consumer's own consumption would affect utility only through its ratio to the benchmark, $\frac{c_{t}}{\nu_{t}^{y}}$, as in Abel $(1990,1999)^{5}$. However, I rule out this case here by restricting $\eta$ to be strictly less than one. ${ }^{6}$

I will rewrite the utility function in equation (11) using the expressions for $\nu_{t}^{y}$ in equation (9) and $\nu_{t+1}^{o}$ in equation (10) to obtain

$$
U_{t}=u_{t}^{y}+\beta u_{t+1}^{o}
$$

${ }^{5}$ In Abel (1990), the benchmark level of consumption in period $t$ depends on the per capita level of consumption in period $t-1$, rather than on the contemporaneous level of per capita consumption. In considering this difference, note that in Abel (1990) a period is one year, but in the current paper a period is one half of an adult lifetime. Also, in Abel (1990), the parameter $\gamma$, which corresponds to $\eta$ in the current notation, is set equal to one in the numerical calibration, though the theoretical analysis does not restrict $\gamma$ to be equal to one.

${ }^{6}$ Although $\eta=1$ has interesting asset pricing implications, this value of $\eta$ changes the nature of the social planner's problem. Specifically, if $\eta=1$, the utility of a representative consumer born at the beginning of period $t$ is unaffected by a doubling of $c_{t}$ and $x_{t+1}$, if $C_{t}, X_{t}, C_{t+1}$, and $X_{t+1}$ are also doubled. 
where

$$
u_{t}^{y}=u_{t}^{y}\left(c_{t}, C_{t}, X_{t}\right) \equiv \frac{1}{1-\alpha}\left(c_{t} C_{t}^{-\eta}\left(\frac{X_{t}}{C_{t}}\right)^{-\eta \varepsilon_{y}}\right)^{1-\alpha}
$$

and

$$
u_{t+1}^{o}=u_{t+1}^{o}\left(x_{t+1}, X_{t+1}, C_{t+1}\right) \equiv \frac{1}{1-\alpha}\left(x_{t+1} X_{t+1}^{-\eta}\left(\frac{X_{t+1}}{C_{t+1}}\right)^{\eta \varepsilon_{o}}\right)^{1-\alpha}
$$

Note that the time subscripts in equations (13) and (14) refer to the time period in which consumption takes place rather than to the period in which the consumer is born. Thus, $u_{t+1}^{o}$ is the felicity during period $t+1$ of an old consumer who was born at the beginning of period $t$.

\section{Competitive Economy}

In this section I examine the behavior of a competitive economy in which consumers have the utility function specified in equation (12) and the aggregate resource constraint is described by equation (4). I will introduce two fiscal instruments, which can be described as a lump-sum pay-as-you-go social security system and a capital income tax. I focus on these two instruments because they will turn out to be useful in directing a competitive economy to a socially optimal balanced growth path, as I will show in Section 5.

First consider the pay-as-you-go social security system. Let $T_{t}^{y}$ be a 
lump-sum tax paid by each young consumer in period $t$, and let $T_{t}^{o}$ be a lump-sum tax paid by each old consumer in period $t$. If $T_{t}^{o}$ is negative, then old consumers are recipients of transfers from the government and (if $\left.T_{t}^{y}>0\right)$ the tax/transfer system involving $T_{t}^{y}$ and $T_{t}^{o}$ has the character of a social security system. I will impose the condition that the social security system is financed on a balanced-budget pay-as-you-go basis by requiring $N_{t} T_{t}^{y}+N_{t-1} T_{t}^{o}=0$, which implies

$$
T_{t}^{o}=-G_{N} T_{t}^{y} .
$$

Social security taxes and benefits are indexed to the level of productivity measured by $A_{t}$. Specifically,

$$
T_{t}^{y}=\frac{A_{t}}{A_{0}} T_{0}^{y} .
$$

The second fiscal instrument is a capital income tax that is rebated via lump-sum transfers to old consumers. Let $\tau_{K}$ be the rate at which (gross) capital income is taxed. The pre-tax, or social, gross rate of return on capital held from period $t$ to period $t+1$ is $f^{\prime}\left(k_{t+1}\right)$. Let $R_{t+1}$ denote the after-tax gross rate of return on capital held from period $t$ to period $t+1$, which is

$$
R_{t+1}=\left(1-\tau_{K}\right) f^{\prime}\left(k_{t+1}\right) .
$$


Pre-tax gross capital income per old consumer in period $t+1$ is the marginal product of capital, $f^{\prime}\left(k_{t+1}\right)$, multiplied by the amount saved by each young consumer in period $t, w_{t}-T_{t}^{y}-C_{t}$. Therefore, the capital income tax per old consumer is $\tau_{K} f^{\prime}\left(k_{t+1}\right)\left(w_{t}-T_{t}^{y}-C_{t}\right)$. Each old consumer in period $t+1$ receives a lump-sum rebate, $q_{t+1}$, of the capital income tax, so

$$
q_{t+1}=\tau_{K} f^{\prime}\left(k_{t+1}\right)\left(w_{t}-T_{t}^{y}-C_{t}\right) .
$$

The lump-sum tax on old consumers, $T_{t+1}^{o}$, and the lump-sum rebate of the capital income tax, $q_{t+1}$, can be combined into a single variable $\widetilde{T}_{t+1}^{o} \equiv$ $T_{t+1}^{o}-q_{t+1}$, which is the net lump-sum tax paid by each old consumer in period $t+1$. I have chosen to specify the separate components, $T_{t+1}^{o}$ and $q_{t+1}$, of $\widetilde{T}_{t+1}^{o}$ to help interpret optimal fiscal policy.

The lifetime budget constraint of a consumer born at the beginning of period $t$, taking account of the lump-sum social security taxes and transfers, the capital income tax, and the lump-sum rebate of the capital income tax, is

$$
x_{t+1}=\left(w_{t}-T_{t}^{y}-c_{t}\right) R_{t+1}-T_{t+1}^{o}+q_{t+1} .
$$

A consumer born at the beginning of period $t$ chooses $c_{t}$ and $x_{t+1}$ to maximize utility in equation (12) subject to the budget constraint in equation 
(19). Along a balanced growth path $\sigma_{t}=\sigma$ and $\frac{C_{t+1}}{C_{t}}=G_{A}$, and this decision problem is isomorphic to the following simple problem:

$$
\max _{c_{t}, x_{t+1}} \frac{1}{1-\alpha} c_{t}^{1-\alpha}+\beta M(\sigma) \sigma^{\alpha} G_{A}^{-\eta(1-\alpha)} \frac{1}{1-\alpha} x_{t+1}^{1-\alpha}
$$

subject to equation (19) where

$$
M(\sigma) \equiv \sigma^{\varepsilon_{M}}
$$

and $^{7}$

$$
\varepsilon_{M} \equiv-\alpha-(1-\alpha) \eta\left(1-\varepsilon_{y}-\varepsilon_{o}\right)<0
$$

To interpret $M(\sigma)$, note that $\beta M(\sigma) G_{A}^{-\alpha-\eta(1-\alpha)}$ equals the private marginal rate of substitution, $M R S^{P}\left(c_{t}, x_{t+1}\right) \equiv \beta \frac{\partial u_{t+1}^{o} / \partial x_{t+1}}{\partial u_{t}^{y} / \partial c_{t}}$, evaluated in equilibrium along a balanced growth path (so that $\left.x_{t+1}=\sigma c_{t+1}=\sigma G_{A} c_{t}\right)$. Thus, $\beta M(\sigma)$ is the private marginal rate of substitution along a balanced growth path in the absence of productivity growth.

In Appendix A I show that along an equilibrium balanced growth path ${ }^{8}$

$$
\beta R M(\sigma)=G_{A}^{\alpha+\eta(1-\alpha)} .
$$

\footnotetext{
${ }^{7}$ To show that $\varepsilon_{M}<0$, rewrite $\varepsilon_{M}$ as $\varepsilon_{M}=-1+(1-\alpha)\left(1-\eta\left(1-\varepsilon_{y}-\varepsilon_{o}\right)\right)$. Since $0 \leq \varepsilon_{y}+\varepsilon_{o} \leq 1$ and $\eta<1$, we have $1-\eta\left(1-\varepsilon_{y}-\varepsilon_{o}\right)>0$. Therefore, since $\alpha>0$, $(1-\alpha)\left(1-\eta\left(1-\varepsilon_{y}-\varepsilon_{o}\right)\right)<1$ and $\varepsilon_{M}<0$.

${ }^{8}$ Liu and Turnovsky (2002) show that with inelastic labor supply and identical infinitely-lived consumers, the steady-state rate of return on capital is not affected by consumption externalities. However, with overlapping generations of finitely-lived con-
} 
Equation (23) is the intertemporal Euler equation of an individual consumer along a balanced growth path. ${ }^{9}$ It describes the long-run relationship between two endogenous variables, the after-tax rate of return, $R$, and the intergenerational relative consumption ratio, $\sigma$. In this relationship the elasticity of $R$ with respect to $\sigma$ is $-\varepsilon_{M}>0$ so that the $R$ and $\sigma$ are positively related.

\section{The Optimal Balanced Growth Path}

In this section I analyze the path of consumption and capital accumulation that would be chosen by a social planner who maximizes a particular social welfare function. The social planner chooses levels of consumption for each consumer, and, in principle, could choose different levels of consumption for two identical consumers born at the same date. However, I will assume that the social planner attaches equal weights to the utility of all consumers in a given generation. Since the consumption of each consumer is too small to affect the per capita consumption of that consumer's generation, all consumers sumers, the equilibrium rate of return along a balanced growth path depends on the consumption externalities as captured by $\eta$ and $M(\sigma)$, which depends on $\eta$, $\varepsilon_{y}$, and $\varepsilon_{o}$, in equation (23).

${ }^{9}$ Since $M R S^{P}\left(c_{t}, x_{t+1}\right)=\beta M(\sigma) G_{A}^{-\alpha-\eta(1-\alpha)}$, equation $(23)$ can be rewritten as $R \times$ $\operatorname{MRS}^{P}\left(c_{t}, x_{t+1}\right)=1$. 
in a given generation have the same benchmark levels of consumption as each other. Therefore, they have the same utility functions as each other, and, since utility is strictly concave in an individual consumer's own consumption, the social planner will choose equal consumption for all consumers in a generation.

Suppose that the social welfare function in period $t$ is

$$
\sum_{j=-1}^{\infty} \rho^{j} G_{N}^{j} U_{t+j}
$$

where

$$
0<\rho G_{N} G_{A}^{(1-\alpha)(1-\eta)}<1
$$

Because the generation born at the beginning of period $t-1$ consumes during period $t$ (as well as during period $t-1$ ), it is important that the social planner assigns a positive weight to $U_{t-1}$ when making decisions at the beginning of period $t$. Therefore, the index $j$ in equation (24) runs from -1 to $\infty$ rather than from 0 to $\infty$. The parameter $\rho$ in the social welfare function is the discount factor applied to the total utility of a given generation relative to the total utility of the preceding generation, which has $\frac{1}{G_{N}}$ as many people as the given generation. ${ }^{10}$ The restriction in equation (25) is necessary and

\footnotetext{
${ }^{10}$ I thank an anonymous referee for suggesting that I apply the discount factor $\rho^{j}$ to the total utility of a generation, $G_{N}^{j} U_{t+j}$, rather than to per capita utility, $U_{t+j}$.
} 
sufficient for the sum in equation (24) to be finite along a balanced growth path. $^{11}$

Since the social planner chooses equal consumption for all consumers in a generation, the utility of a representative consumer born at the beginning of period $t$ is found by setting $c_{t}=C_{t}$ in equation (13) and $x_{t+1}=X_{t+1}$ in equation (14), using the definition of the intergenerational consumption ratio, $\sigma_{t} \equiv \frac{X_{t}}{C_{t}}$, and substituting equations (13) and (14) into equation (12) to obtain

$$
U_{t}=\frac{1}{1-\alpha}\left(C_{t}^{1-\eta} \sigma_{t}^{-\eta \varepsilon_{y}}\right)^{1-\alpha}+\beta \frac{1}{1-\alpha}\left(C_{t+1}^{1-\eta} \sigma_{t+1}^{1-\eta+\eta \varepsilon_{o}}\right)^{1-\alpha}
$$

The standard Modified Golden Rule in overlapping generations economies ${ }^{12}$ is a special case of the current model in which $\eta=0$ so that benchmarks do not enter the utility function. In this special case, the social welfare function is maximized by an appropriate path of the aggregate capital stock, which implies an appropriate path of aggregate consumption. In the absence of consumption externalities $(\eta=0)$ the social planner has no particular target

\footnotetext{
${ }^{11}$ Along a balanced growth path, $\frac{C_{t+1}}{C_{t}}=\frac{X_{t+1}}{X_{t}}=G_{A}$, which implies that $\frac{U_{t+1}}{U_{t}}=$ $G_{A}^{(1-\alpha)(1-\eta)}$. Therefore, along a balanced growth path, equation (24) is a geometric series in which each term is $\rho G_{N} G_{A}^{(1-\alpha)(1-\eta)}$ times as large as the preceding term. This series has a finite sum if and only if $0<\rho G_{N} G_{A}^{(1-\alpha)(1-\eta)}<1$.

${ }^{12}$ See, for example, Samuelson (1968) and Blanchard and Fischer (1989, p. 100).
} 
for the intergenerational consumption ratio, $\sigma_{t}$. Indeed, the social welfare function is maximized by the intergenerational allocation of consumption that arises when individual consumers facing market rates of return-without capital income taxes-choose their optimal allocations of consumption over their own lifetimes.

The introduction of consumption externalities $(\eta>0)$ implies that the social planner must target the intergenerational consumption ratio as well as the path of capital accumulation. We can think of the social planner as first choosing the optimal path of aggregate consumption and capital accumulation. Then, given this optimal path of aggregate consumption, the social planner chooses the intergenerational consumption ratio $\sigma_{t}$. Unfortunately, the social planner's objective function is not concave in $\sigma_{t}$ for all permissible parameter values. To assure that the optimal value of $\sigma_{t}$ is characterized by the first-order conditions derived in Appendix B, I will assume henceforth that $\alpha \geq 1$. This assumption does not guarantee that the social planner's objective function is concave in $\sigma_{t}$, but it does imply that the value of the social welfare function approaches $-\infty$ both as $\sigma_{t}$ approaches 0 and as $\sigma_{t}$ approaches $\infty .^{13}$ Therefore, the optimal value of $\sigma_{t}$ is strictly positive and

\footnotetext{
${ }^{13}$ Equation (14) implies that when $x_{t}=X_{t}, u_{t}^{o}=\frac{1}{1-\alpha}\left(X_{t}^{1-\eta+\eta \varepsilon_{o}} C_{t}^{-\eta \varepsilon_{o}}\right)^{1-\alpha}$. For a
} 
finite. Since the social welfare function is continuously differentiable in $\sigma_{t}$ for positive $\sigma_{t}$, the optimal value of $\sigma_{t}$ will satisfy the first-order condition.

Let $k^{*}$ denote the socially optimal value of $k_{t}$ along a balanced growth path. As shown in Appendix B, $k^{*}$ satisfies

$$
\rho f^{\prime}\left(k^{*}\right)=G_{A}^{\alpha+\eta(1-\alpha)}
$$

Equation (27) is a generalization of the well-known Modified Golden Rule. In the standard formulation of preferences without benchmark levels of consumption, $\eta=0$ and the Modified Golden Rule in equation (27) takes the more familiar form, $\rho f^{\prime}\left(k^{*}\right)=G_{A}^{\alpha}{ }^{14}$ In the absence of productivity growth given amount of aggregate consumption in period $t, \lim _{\sigma_{t} \rightarrow 0} X_{t}=0$. If $\alpha>1$, then $\lim _{\sigma_{t} \rightarrow 0} u_{t}^{o}=-\infty$. If $\alpha=1$, then $u_{t}^{o}=\left(1-\eta+\eta \varepsilon_{o}\right) \ln X_{t}-\eta \varepsilon_{o} \ln C_{t}$ so $\lim _{\sigma_{t} \rightarrow 0} u_{t}^{o}=$ $-\infty$. Therefore, if $\alpha \geq 1$, then $\lim _{\sigma_{t} \rightarrow 0} u_{t}^{o}=-\infty$. Equation (13) implies that when $c_{t}=C_{t}, u_{t}^{y}=\frac{1}{1-\alpha}\left(C_{t}^{1-\eta+\eta \varepsilon_{y}} X_{t}^{-\eta \varepsilon_{y}}\right)^{1-\alpha}$. For a given amount of aggregate consumption in period $t, \lim _{\sigma_{t} \rightarrow \infty} C_{t}=0$. If $\alpha>1$, then $\lim _{\sigma_{t} \rightarrow \infty} u_{t}^{y}=-\infty$. If $\alpha=1$, then $u_{t}^{y}=\left(1-\eta+\eta \varepsilon_{y}\right) \ln C_{t}-\eta \varepsilon_{y} \ln X_{t}$ so $\lim _{\sigma_{t} \rightarrow \infty} u_{t}^{y}=-\infty$. Therefore, if $\alpha \geq 1$, then $\lim _{\sigma_{t} \rightarrow \infty} u_{t}^{y}=-\infty$.

${ }^{14}$ The formulations of the Modified Golden Rule presented by Samuelson (1968) and Blanchard and Fischer (1989) include the population growth rate $G_{N}$, but equation (27) does not explicitly include $G_{N}$. Samuelson and Blanchard and Fischer use a social welfare function that is a weighted average of the utility of the representative consumer in each generation, but the social welfare function in equation (24) is a weighted average of the total 
$\left(G_{A}=1\right)$, the value of $k^{*}$ is not affected by the introduction of benchmark levels of consumption. In the presence of productivity growth $\left(G_{A}>1\right)$, the introduction of benchmark levels of consumption will increase $k^{*}$ if $\alpha>1$, but will have no effect on $k^{*}$ if $\alpha=1$.

Let $\sigma^{*}$ denote the optimal value of $\sigma_{t}$ along a balanced growth path. It is convenient to analyze $\sigma^{*}$ by defining the function

$$
\Psi(r) \equiv \frac{1-\eta+\eta \varepsilon_{o}+\eta \varepsilon_{o} r}{\left(1-\eta+\eta \varepsilon_{y}\right) r+\eta \varepsilon_{y}} r, \quad \text { for } r>0 .
$$

Appendix E shows that $\Psi\left(\frac{\sigma^{*}}{G_{N}}\right)$ equals the ratio $\frac{M R S^{S}\left(C_{t}, X_{t+1}\right)}{M R S^{P}\left(c_{t}, x_{t+1}\right)}$, where $M R S^{S}\left(C_{t}, X_{t+1}\right)$ is the social marginal rate of substitution between current consumption of the young and next period's consumption of the old along a socially optimal balanced growth path, and $\operatorname{MRS}^{P}\left(c_{t}, x_{t+1}\right)$ is the private marginal rate of substitution between these two consumptions along a socially optimal balanced growth path. The function $\Psi(r)$ is useful in characterizing the socially optimal balanced growth path. Appendix D proves the following lemma, which describes various properties of $\Psi(r)$.

utility of each generation. With a constant population growth rate $G_{N}$, this difference is simply a normalization. To illustrate, define $\widehat{\rho} \equiv \rho G_{N}$. The social welfare function in equation (24) can be written as $\sum_{j=-1}^{\infty} \widehat{\rho}^{j} U_{t+j}$ and the Modified Golden Rule in equation (27) can be written in the more familiar form as $\widehat{\rho} f^{\prime}\left(k^{*}\right)=G_{N} G_{A}^{\alpha}$ when $\eta=0$. 
Lemma 1 The function $\Psi(r)$ defined in equation (28) for $r>0$ has the following properties:

(a) $\Psi(r)>0$;

(b) $\Psi^{\prime}(r) \geq 0$, with strict inequality if $\eta \varepsilon_{y}>0$ or if $\eta \varepsilon_{o}>0$;

(c) $0 \leq \varepsilon_{\Psi} \equiv \frac{r \Psi^{\prime}(r)}{\Psi(r)}<1 ;$

(d) if $\eta \varepsilon_{y}=\eta \varepsilon_{o}=0$, then $\Psi(r) \equiv 1$;

(e) if $\eta \varepsilon_{y}>0$ and $\eta \varepsilon_{o}>0$, then $\Psi\left(\frac{\varepsilon_{y}}{\varepsilon_{o}}\right)=1$;

(f) if $\eta \varepsilon_{o}=0$ and $\eta \varepsilon_{y}>0$, then $\Psi(r)<1$;

(g) if $\eta \varepsilon_{y}=0$ and $\eta \varepsilon_{o}>0$, then $\Psi(r)>1$;

(h) (i) $\lim _{r \rightarrow 0} \frac{1}{r} \Psi(r)=\frac{1-\eta+\eta \varepsilon_{o}}{\eta \varepsilon_{y}}>0$, if $\eta \varepsilon_{y}>0$;

(ii) $\lim _{r \rightarrow 0} \frac{1}{r} \Psi(r)=\infty$, if $\eta \varepsilon_{y}=0$;

(i) $\lim _{r \rightarrow \infty} \frac{1}{r} \Psi(r)=\frac{\eta \varepsilon_{o}}{1-\eta+\eta \varepsilon_{y}}$.

Parts (a), (b), and (c) of Lemma 1 state that $\Psi(r)$ is positive, increasing, and has an elasticity with respect to $r$ that is less one. When the private marginal rate of substitution, $M R S^{P}\left(c_{t}, x_{t+1}\right)$, equals the social marginal rate of substitution, $M R S^{S}\left(C_{t}, X_{t+1}\right)$, along a socially optimal balanced growth path, $\Psi(r)=1 . \quad$ Parts (d) and (e) of Lemma 1 describe cases in which $\Psi(r)=1$, and parts (f) and (g) provide sufficient conditions for $\Psi(r)$ to be, respectively, less than one and greater than one. Finally, parts 
(h) and (i) of Lemma 1 describe limiting behavior of $\Psi(r)$ that is helpful in ensuring that the characterization of optimal $\sigma$ presented later is correct for the case in which $\alpha=1$.

Appendix B shows that the optimal value of the intergenerational consumption ratio $\sigma^{*}$ satisfies

$$
\beta M\left(\sigma^{*}\right) \Psi\left(\frac{\sigma^{*}}{G_{N}}\right)=\rho
$$

To interpret equation (29), use equation (27) to show that $G_{A}^{\alpha+\eta(1-\alpha)} / f^{\prime}\left(k^{*}\right)$ equals the social discount factor $\rho$, and substitute this expression for $\rho$ into equation (29) to obtain

$$
\left[\beta M\left(\sigma^{*}\right) G_{A}^{-\alpha-\eta(1-\alpha)} \Psi\left(\frac{\sigma^{*}}{G_{N}}\right)\right] f^{\prime}\left(k^{*}\right)=1 .
$$

Since the private marginal rate of substitution, $\operatorname{MR} S^{P}\left(c_{t}, x_{t+1}\right)$, equals $\beta M\left(\sigma^{*}\right) G_{A}^{-\alpha-\eta(1-\alpha)}$, and since $\Psi\left(\frac{\sigma^{*}}{G_{N}}\right)$ is the ratio of the social marginal rate of substitution to the private marginal rate of substitution, the term in square brackets in equation (30) is the social marginal rate of substitution, $M R S^{S}\left(C_{t}, X_{t+1}\right)$. Equation (30) simply states that the product of the social marginal rate of substitution and the social rate of return, $f^{\prime}\left(k^{*}\right)$, equals one, which is a standard Euler condition for intertemporal optimization.

Equation (29) characterizes the optimal intergenerational consumption 
ratio, $\sigma^{*}$. I will devote the remainder of this section to analyzing the properties and implications of this equation. I will focus on two cases in which I can prove that there is a unique positive value of $\sigma$ that satisfies equation (29):

- Case I: $\alpha>1$.

- Case II: $\alpha=1$ and $0<\frac{\eta \varepsilon_{o}}{1-\eta+\eta \varepsilon_{y}}<\frac{\rho G_{N}}{\beta}<\frac{1-\eta+\eta \varepsilon_{o}}{\eta \varepsilon_{y}}$.

The following lemma, which is proved in Appendix D, is useful in analyzing these cases.

Lemma 2 In Cases I and II, $\varepsilon_{M}+\varepsilon_{\Psi}<0$ for $r>0$.

Lemma 2 implies that the left side of equation (29) is a strictly decreasing function of $\sigma$ in Cases I and II, so that if there is a value of $\sigma$ that satisfies this equation, that value is unique. Also, because the left side of equation (29) is continuous in nonnegative $\sigma$, the existence of a positive value of $\sigma$ that satisfies this equation can be proved by showing that the left side is greater than $\rho$ for $\sigma=0$ and is less than $\rho$ for sufficiently large positive $\sigma$. These results are summarized in the following proposition, which is proved in Appendix D. 
Proposition 1 In Cases I and II, there exists a unique positive value of $\sigma$ that satisfies equation (29).

Anticipating the results in Section 5.1 on the optimal capital income tax rate, it will be important to determine whether the optimal value of $\sigma$ is greater than, equal to, or less than $\frac{\varepsilon_{y} G_{N}}{\varepsilon_{o}}$. Lemma 2 implies that $\beta M(\sigma) \Psi\left(\frac{\sigma}{G_{N}}\right)$ is strictly decreasing in $\sigma$ so that if $\beta M(z) \Psi\left(\frac{z}{G_{N}}\right)>\rho$, then $\sigma^{*}$ is greater than $z$. Similarly, if $\beta M(z) \Psi\left(\frac{z}{G_{N}}\right)<\rho$, then $\sigma^{*}$ is less than $z$. These arguments are summarized in the following lemma.

Lemma 3 In Cases I and II, sign $\left[\sigma^{*}-z\right]=\operatorname{sign}\left[M(z) \Psi\left(\frac{z}{G_{N}}\right)-\frac{\rho}{\beta}\right]$.

Part (e) of Lemma 1 states that $\Psi\left(\frac{\varepsilon_{y}}{\varepsilon_{o}}\right)=1$ if $\eta \varepsilon_{y}>0$ and $\eta \varepsilon_{o}>0$, so that Lemma 3 implies

Proposition 2 In Cases I and II, $\operatorname{sign}\left[\sigma^{*}-\frac{\varepsilon_{y} G_{N}}{\varepsilon_{o}}\right]=\operatorname{sign}\left[M\left(\frac{\varepsilon_{y} G_{N}}{\varepsilon_{o}}\right)-\frac{\rho}{\beta}\right]$, if $\eta \varepsilon_{y}>0$ and $\eta \varepsilon_{o}>0$.

Proposition 2 provides a condition on exogenous parameters that determines whether $\sigma^{*}$ is greater than, equal to, or less $\frac{\varepsilon^{y} G_{N}}{\varepsilon^{o}}$. It is easiest to interpret this condition in the case in which both benchmarks are equallyweighted geometric averages of the contemporaneous consumption of all con- 
sumers, so that $\theta_{y}=\theta_{o}=1$, which implies that $\frac{\varepsilon_{y} G_{N}}{\varepsilon_{o}}=1$. The fact that $M(1)=1$ implies the following corollary.

Corollary 1 In Cases $I$ and II, if $\theta_{y}=\theta_{o}=1$, then sign $\left[\sigma^{*}-1\right]=$ $\operatorname{sign}[\beta-\rho]$.

According to Corollary 1, if both benchmarks are equally-weighted geometric averages of the consumption of all consumers, a social planner with discount factor $\rho$ equal to the time preference discount factor $\beta$ in individual utility functions will equalize the consumption of young and old consumers in each period along a balanced growth path. If the social planner is more patient than individuals, so that $\rho>\beta$, then the social planner will allocate a higher level of consumption to young consumers than to old consumers in each period along a balanced growth path. To understand this result, consider the social planner's problem in period $t$ along a balanced growth path. Suppose that the social planner has chosen how much capital to carry into period $t+1$, and is deciding how to allocate the remaining output to $C_{t}$ and $X_{t}$. In period $t$, having chosen $k_{t+1}$, the social planner chooses $C_{t}$ and $X_{t}$ to maximize

$$
u_{t}^{y}\left(C_{t}, C_{t}, X_{t}\right)+\rho^{-1} G_{N}^{-1} \beta u_{t}^{o}\left(X_{t}, X_{t}, C_{t}\right)
$$


where $u_{t}^{y}()$ and $u_{t}^{o}()$ are defined equations (13) and (14). The first term in equation (31), $u_{t}^{y}\left(C_{t}, C_{t}, X_{t}\right)$, is increasing in $C_{t}$ and decreasing in $X_{t}$, and the second term, $\rho^{-1} G_{N}^{-1} \beta u_{t}^{o}\left(X_{t}, X_{t}, C_{t}\right)$, is increasing in $X_{t}$ and decreasing in $C_{t}$. An increase in $\frac{\rho}{\beta}$ reduces the weight on $u_{t}^{o}\left(X_{t}, X_{t}, C_{t}\right)$ and thus leads the social planner to shift current consumption away from $X_{t}$ toward $C_{t}$, which is a reduction in $\sigma_{t}$. This argument suggests that the optimal value of $\sigma$ is a decreasing function of the ratio $\frac{\rho}{\beta}$. The argument does not depend on the assumption in Corollary 1 that $\varepsilon_{y} G_{N}=\varepsilon_{o}$, and Proposition 3 below relaxes this assumption.

To analyze formally the effects of $\rho$ and $\beta$ on the optimal value of $\sigma$, totally differentiate equation (29) with respect to $\sigma$ and $\frac{\rho}{\beta}$ to obtain

$$
\left(\varepsilon_{M}+\varepsilon_{\Psi}\right) \frac{d \sigma}{\sigma}=\frac{d(\rho / \beta)}{\rho / \beta} .
$$

Equation (32) and Lemma 2 imply the following proposition.

Proposition 3 In Cases $I$ and $I I, \frac{d \sigma^{*}}{d(\rho / \beta)}=\frac{1}{\varepsilon_{M}+\varepsilon_{\Psi}} \frac{\sigma \beta}{\rho}<0$.

Since the functions $M()$ and $\Psi()$ depend on preference parameters but not on technology, inspection of equation (29) proves the following proposition. 
Proposition $4 \sigma^{*}$ is independent of the specification of the production function, $f\left(k_{t}\right)$, and of the growth rate of productivity, $G_{A}$.

\section{$5 \quad$ Fiscal Policy Along the Optimal Balanced Growth Path}

In Section 4, I derived the values of the intergenerational relative consumption ratio, $\sigma^{*}$, and the capital-labor ratio, $k^{*}$, along the socially optimal balanced growth path. In this section, I derive the fiscal policies-specifically the tax and transfer policies-that induce a competitive economy to attain these values along a balanced growth path. The strategy for determining the optimal tax and transfer policies is to assume that the competitive economy has attained the socially optimal balanced growth path and then to determine the values of the tax and transfer parameters that are consistent with competitive equilibrium along this balanced growth path. I will confine attention to deterministic-indeed constant-tax rates. 


\subsection{Optimal Tax on Capital Income}

To avoid considerations of dynamic consistency that can arise with a capital income tax, I assume that the fiscal authority can credibly commit to maintain a constant tax rate on capital income. To calculate the optimal tax rate on capital income, divide the expression for the competitive private rate of return on capital implied by equation (23) by the expression for the optimal marginal product of capital in equation (27), to obtain

$$
\frac{R}{f^{\prime}\left(k^{*}\right)}=\frac{\rho}{\beta M\left(\sigma^{*}\right)}
$$

Use equation (17) to rewrite the left side of equation (33) as $1-\tau_{K}$. Use

equation (29) to rewrite the right side of equation (33) as $\Psi\left(\frac{\sigma^{*}}{G_{N}}\right)$. Therefore, equation (33) can be rearranged to obtain

$$
\tau_{K}^{*}=1-\Psi\left(\frac{\sigma^{*}}{G_{N}}\right)
$$

where $\tau_{K}^{*}$ is the optimal tax rate on gross capital income. ${ }^{15}$ The expression in equation (34), along with the fact that the function $\Psi()$ depends only on

\footnotetext{
${ }^{15}$ Erosa and Gervais (2000) and Garriga (2001) show that it is generally optimal to tax (or subsidize) capital income if individuals have labor-leisure choices throughout their lives. However, this result does not apply to the model I present here because labor is inelastically supplied in the first period of life and zero labor is supplied in the second period of life. In the model I present here, the tax rate on capital along the socially optimal
} 
preference parameters, implies the following corollary to Proposition $4 .{ }^{16}$

Corollary 2 The optimal tax rate on capital income, $\tau_{K}^{*}$, is independent of the specification of the production function, $f\left(k_{t}\right)$, and of the growth rate of productivity, $G_{A}$.

To understand the role of the capital income tax along the socially optimal balanced growth path, recall that $\operatorname{MRS}^{S}\left(C_{t}, X_{t+1}\right)=\Psi\left(\frac{\sigma^{*}}{G_{N}}\right) \times M R S^{P}\left(c_{t}, x_{t+1}\right)$, so $\Psi\left(\frac{\sigma^{*}}{G_{N}}\right)$ represents the wedge between the private and social marginal rates of substitution along a socially optimal balanced growth path. Along a balanced growth path, equation (17) states that $R=\left(1-\tau_{K}\right) f^{\prime}(k)$, so that $1-\tau_{K}$ is the wedge between the private rate of return, $R$, and the social rate of return, $f^{\prime}(k)$. Setting $1-\tau_{K}=\Psi\left(\frac{\sigma^{*}}{G_{N}}\right)$ makes the wedge between the private and social rates of return exactly offset the wedge between the balanced growth path would be zero in the absence of the consumption externalities that I study here.

${ }^{16}$ Ljungqvist and Uhlig (2000) derive a related result in a model with identical consumers and endogenous labor supply, but without capital. They show that the optimal tax rate on labor income is independent of technology, if, as in the model I present here, the benchmark level of consumption depends only on the contemporaneous consumption of other consumers. 
private and social marginal rates of substitution. ${ }^{17}$

Equation (34) implies that the sign of the optimal capital income tax rate depends on whether $\Psi\left(\frac{\sigma^{*}}{G_{N}}\right)$ is greater than, less than, or equal to one. Specifically, if $\Psi\left(\frac{\sigma^{*}}{G_{N}}\right)<1$, the optimal capital income tax rate is positive; if $\Psi\left(\frac{\sigma^{*}}{G_{N}}\right)>1$, the optimal capital income tax rate is negative; and if $\Psi\left(\frac{\sigma^{*}}{G_{N}}\right)=1$, the optimal capital income tax rate is zero. Properties (f), (g), and (d) in Lemma 1 imply, respectively, parts (a), (b), and (c) in the following proposition.

Proposition 5 (a) If $\eta \varepsilon_{o}=0$ and $\eta \varepsilon_{y}>0$, then $\tau_{K}^{*}>0$. (b) If $\eta \varepsilon_{y}=0$ and $\eta \varepsilon_{o}>0$, then $\tau_{K}^{*}<0$. (c) If $\eta \varepsilon_{y}=\eta \varepsilon_{o}=0$, then $\tau_{K}^{*}=0$.

If $\eta \varepsilon_{o}=0$ and $\eta \varepsilon_{y}>0$, the consumption of old consumers imposes a negative externality on young consumers. Since old consumers do not take account of this externality, the value of $\sigma \equiv \frac{X_{t}}{C_{t}}$ in a competitive economy without taxes would be higher than in the social optimum. To reduce the

\footnotetext{
${ }^{17}$ Along the socially optimal balanced growth path, $1=\operatorname{MRS} S\left(C_{t}, X_{t+1}\right) \times f^{\prime}\left(k^{*}\right)=$ $\Psi\left(\frac{\sigma^{*}}{G_{N}}\right) \times M R S^{P}\left(c_{t}, x_{t+1}\right) \times f^{\prime}\left(k^{*}\right)=\operatorname{MRS}^{P}\left(c_{t}, x_{t+1}\right) \times\left(1-\tau_{K}^{*}\right) f^{\prime}\left(k^{*}\right)=1$, where the first equality reflects the Euler equation for the socially optimal intertemporal allocation of consumption, the second equality uses $M R S^{S}\left(C_{t}, X_{t+1}\right)=\Psi\left(\frac{\sigma^{*}}{G_{N}}\right) \times M R S^{P}\left(c_{t}, x_{t+1}\right)$, the third equality uses equation (34), and the fourth equality reflects the Euler equation for private consumers.
} 
value of $\sigma$ in a competitive economy, the government could reduce the private rate of return by introducing a positive tax rate on capital income. ${ }^{18}$ By contrast, if $\eta \varepsilon_{y}=0$ and $\eta \varepsilon_{o}>0$, the consumption of young consumers imposes a negative externality on old consumers, so the value of $\sigma \equiv \frac{X_{t}}{C_{t}}$ in a competitive economy without taxes is lower than in the social optimum. In this case, a negative tax rate on capital income would increase the private rate of return and increase $\sigma$. If neither generation imposes an externality on the other generation $\left(\eta \varepsilon_{y}=\eta \varepsilon_{o}=0\right)$, the optimal capital income tax rate is zero. ${ }^{19}$

\footnotetext{
${ }^{18}$ Recall from equation (23) and the discussion below that equation that $\sigma$ is positively related to $R$ along a competitive balanced growth path.

${ }^{19}$ In de la Croix and Michel (1999), the optimal tax rate on capital income is negative because of an asymmetry in the specification of benchmark consumption in the utility function. In their model, consumers live for three periods, and consume during middle age and old age. Middle-aged consumers have a benchmark level of consumption equal to the middle-age consumption of the previous generation, but there is no benchmark for old-age consumption. However, if their model were altered so that there is no benchmark for middle-aged consumption, but there is a benchmark for old-age consumption equal to the old-age consumption of the previous generation, then the optimal tax rate on capital would be positive, rather than negative. In the model I present here, in which consumers live for two periods (and the benchmarks depend on the contemporaneous rather than the lagged consumption of others), there are benchmark levels of consumption in both periods
} 
Proposition 5 gives the sign of the optimal capital income tax rate if $\eta \varepsilon_{y} \varepsilon_{o}=0$. For the case in which $\eta \varepsilon_{y} \varepsilon_{o}>0$, equation (34) and parts (b) and (e) of Lemma 1 imply

$$
\operatorname{sign}\left[\tau_{K}^{*}\right]=-\operatorname{sign}\left[\sigma^{*}-\frac{\varepsilon_{y} G_{N}}{\varepsilon_{o}}\right]
$$

Equation (35) and Proposition 2 imply the following proposition.

Proposition 6 In Cases $I$ and $I I$, if $\eta \varepsilon_{o}>0$ and $\eta \varepsilon_{y}>0$, then sign $\left[\tau_{K}^{*}\right]=$ $\operatorname{sign}\left[\frac{\rho}{\beta}-M\left(\frac{\varepsilon_{y} G_{N}}{\varepsilon_{o}}\right)\right]$.

Since $\rho, \beta, G_{N}, \varepsilon_{y}$, and $\varepsilon_{o}$ are exogenous parameters, Proposition 6 provides a condition on exogenous parameters that determines whether the optimal capital income tax rate is positive, negative, or zero. This condition takes a simple form when the benchmarks are equally-weighted geometric averages of the consumption of all consumers so that $\theta_{y}=\theta_{o}=1$, which implies that $\frac{\varepsilon_{y} G_{N}}{\varepsilon_{o}}=1$

Corollary 3 In Cases $I$ and II, if $\eta>0$ and if $\theta_{y}=\theta_{o}=1$, then $\operatorname{sign}\left[\tau_{K}^{*}\right]$ $=\operatorname{sign}[\rho-\beta]$.

of a consumer's life and the optimal tax rate on capital could be negative, positive, or zero, as illustrated by Proposition 5. 
With benchmarks that are equally-weighted geometric averages of consumption, if the social discount factor, $\rho$, equals the time preference discount factor, $\beta$, the optimal tax rate on capital income is zero. Perhaps surprisingly, if the social planner is more patient than individuals, so that $\rho>\beta$, the optimal tax rate is positive. If $\rho>\beta$, the social planner wants to shift consumption toward later generations of consumers, and thus in each period wants to shift consumption away from old consumers toward young consumers. By imposing a positive tax rate on capital income, consumers are induced to shift consumption away from old age toward their youth.

Equation (34) shows that for given values of $\eta, \varepsilon_{y}$, and $\varepsilon_{o}$, the optimal value of the tax rate on capital income depends only on $\frac{\sigma^{*}}{G_{N}}$. Differentiating equation (34) and using part (b) of Lemma 1 proves the following proposition.

Proposition 7 For given values of $\eta \varepsilon_{y}$ and $\eta \varepsilon_{o}$ in Cases I and II, if $\eta \varepsilon_{y}>0$ or if $\eta \varepsilon_{o}>0$, then $\frac{d \tau_{K}^{*}}{d \sigma *}=-\Psi^{\prime}\left(\frac{\sigma^{*}}{G_{N}}\right) \frac{1}{G_{N}}<0$.

Corollary 4 In Cases I and II, $\frac{d \tau_{K}^{*}}{d\left(\frac{\rho}{\beta}\right)}>0$.

As suggested by the discussion following Corollary 3, an increase in $\frac{\rho}{\beta}$ shifts the optimal consumption toward later, younger, generations. The desired increase in consumption of the young relative to consumption of the 
old can be achieved by an increase in $\tau_{K}^{*}$, which reduces the private rate of return on capital and induces consumers to shift consumption from old age toward youth.

\subsection{Optimal Lump-Sum Intergenerational Tax/Transfer}

Now consider the optimal lump-sum intergenerational tax/transfer, which can be interpreted as a lump-sum pay-as-you-go social security system. In period $t$ along a balanced growth path, the aggregate tax on young consumers, which follows from equation (16), is $N_{t} \frac{A_{t}}{A_{0}} T_{0}^{y}$ and total output is $A_{t} N_{t} f\left(k_{t}\right)$. Define $\tau^{y *} \equiv \frac{T_{0}^{y}}{A_{0} f\left(k^{*}\right)}$ as the tax on young consumers, expressed as a fraction of total output, along the optimal balanced growth path. I show in Appendix $\mathrm{C}$ that the optimal tax on young consumers, $\tau^{y *}$, is

$$
\tau^{y *}=\tau^{y *}\left(\sigma^{*}, \Lambda\right) \equiv \frac{\sigma^{*} \Lambda-G_{N}}{\sigma^{*}+G_{N}} \varepsilon_{f},
$$

where ${ }^{20}$

$$
\Lambda \equiv \frac{1-\varepsilon_{f}}{\varepsilon_{f}}-\rho G_{N} G_{A}^{(1-\alpha)(1-\eta)}>-1 .
$$

${ }^{20}$ To prove that $\Lambda>-1$, rewrite $\Lambda$ as $\Lambda=\left[\frac{1}{\varepsilon_{f}}-\rho G_{N} G_{A}^{(1-\alpha)(1-\eta)}\right]-1$. Observe that the term in brackets is positive because $\varepsilon_{f}<1$ implies $\frac{1}{\varepsilon_{f}}>1$ and equation (25) states that $\rho G_{N} G_{A}^{(1-\alpha)(1-\eta)}<1$. Since the term in brackets is positive, $\Lambda>-1$. 
Equation (36) expresses $\tau^{y *}$ as a function of an endogenous variable $\left(\sigma^{*}\right)$ and a function of parameters $(\Lambda)$. The following lemma describes the effect of the endogenous variable, $\sigma^{*}$, on $\tau^{y *}$.

Lemma $4 \frac{\partial \tau^{y *}\left(\sigma^{*}, \Lambda\right)}{\partial \sigma^{*}}=\frac{\Lambda+1}{\left(\sigma^{*}+G_{N}\right)^{2}} G_{N} \varepsilon_{f}>0$.

Lemma 4 states that if the optimal intergenerational consumption ratio, $\sigma^{*}$, increases, the optimal lump-sum tax on young consumers, $\tau^{y *}$, increases. To understand this result, consider an increase in $\tau^{y}$, which transfers resources from young consumers to old consumers. An increase in the tax on young consumers reduces their saving, and an increase in the transfer to old consumers also reduces saving by consumers when they are young. The reduction in saving reduces the capital-labor ratio, $k$, along a balanced growth path. The reduction in $k$ increases the social rate of return, $f^{\prime}(k)$, which increases the private rate of return, $R$. The increase in the private rate of return, $R$, induces consumers to substitute from current consumption to future consumption, thereby increasing the intergenerational consumption ratio, $\sigma$. Thus, an increase in the lump-sum tax, $\tau^{y}$, can be used to increase the intergenerational consumption ratio, $\sigma$, as stated by Lemma 4 .

Lemma 4 can be applied to determine the effect on $\tau^{y *}$ of a change in the time preference discount factor of consumers, $\beta$, because $\beta$ affects $\sigma^{*}$, but 
has no effect on $\Lambda$. Proposition 3 implies that an increase in $\beta$ increases $\sigma^{*}$, which, according to Lemma 4 , increases $\tau^{y *}$. This reasoning proves the following proposition.

Proposition 8 In Cases $I$ and $I I, \frac{d \tau^{y *}}{d \beta}>0$.

An increase in the time preference discount factor, $\beta$, increases the amount of saving in the competitive economy and thus would increase the capitallabor ratio to a level higher than the Modified Golden Rule level, $k^{*}$. An increase in the tax levied on young workers can offset the increase in saving and maintain the capital-labor ratio equal to $k^{*}$.

The effect of $\rho$ on $\tau^{y *}$ operates through two channels: an increase in $\rho$ reduces $\sigma^{*}$ (Proposition 3 ), which reduces $\tau^{y^{*}}$; and an increase in $\rho$ reduces $\Lambda$, which also reduces $\tau^{y *}$. This argument proves the following proposition.

Proposition 9 In Cases I and II, $\frac{d \tau^{y *}}{d \rho}<0$.

An increase in the social discount factor, $\rho$, increases the Modified Golden Rule capital-labor ratio, $k^{*}$, and requires an increase in saving, which can be induced by a reduction in the lump-sum tax on young workers.

I have referred to the lump-sum intergenerational tax/transfer system as a social security system, because it transfers resources from young consumers 
to old consumers, if $\tau^{y}>0$. However, it is possible for $\tau^{y}$ to be negative, in which case the tax/transfer system is a "reverse social security system" transferring resources from old consumers to young consumers. It is evident from equation (36) that the sign of the optimal value of $\tau^{y *}$ is the same as the sign of $\sigma^{*} \Lambda-G_{N}$. Therefore, if $\Lambda>0$, the sign of $\tau^{y *}$ is the same as the sign of $\sigma^{*}-\Lambda^{-1} G_{N}$, which, according to Lemma 3 , is the same as the sign of $M\left(\Lambda^{-1} G_{N}\right) \Psi\left(\Lambda^{-1}\right)-\frac{\rho}{\beta}$. The following proposition provides the condition on the exogenous parameter $\Lambda$ that determines the sign of $\tau^{y *}$.

Proposition 10 In Cases $I$ and II, if $\Lambda \leq 0$, then $\tau^{y *}<0$, and if $\Lambda>0$, then $\operatorname{sign}\left[\tau^{y *}\right]=\operatorname{sign}\left[M\left(\Lambda^{-1} G_{N}\right) \Psi\left(\Lambda^{-1}\right)-\frac{\rho}{\beta}\right]$.

\subsection{Numerical Example}

I have derived expressions for the optimal values of the lump-sum tax levied on young consumers, $\tau^{y *}$, and the capital income tax rate, $\tau_{K}^{*}$. I have also derived conditions to determine whether each of the optimal tax rates is positive or negative. In this section, I provide a numerical example, including a modest sensitivity analysis, to illustrate that both $\tau^{y *}$ and $\tau_{K}^{*}$ can be positive in plausible cases.

In this example, I assume that the labor share in income is constant and 
equal to $\frac{2}{3}$, which implies that $\varepsilon_{f}=\frac{1}{3}$. I assume that the curvature parameter $\alpha$ in the utility function equals 4, which implies that the intertemporal elasticity of substitution equals 0.25 . To specify the values of the parameters $\rho, \beta, G_{A}$, and $G_{N}$, I need to specify the length of a time period. Since a time period in the model is one half of an adult lifetime, I will assume that a period is 30 years. I set the time preference discount factor of consumers, $\beta$, equal to $(0.98)^{30}$, so that the rate of time preference is approximately $2 \%$ per year. I assume that the social planner is more patient than individual consumers and set the social discount factor, $\rho$, equal to $(0.99)^{30}$, which implies that the social rate of time preference is approximately $1 \%$ per year. Multifactor productivity in the United States grew at the rate of $1.2 \%$ per year from 1948 to 1998 . In the model in this paper, labor-augmenting productivity growth is the only source of multifactor productivity growth. Attributing all of the growth in multifactor productivity to growth in labor-augmenting productivity, $A$, implies that the growth rate of $A$ is $\left(\frac{1}{1-\varepsilon_{f}}\right)(1.2 \%)$ per year. ${ }^{21}$ Since $\varepsilon_{f}=\frac{1}{3}$, the growth rate of $A$ is $1.8 \%$ per year, and $G_{A}=(1.018)^{30}$. During ${ }^{21}$ If the aggregate production function is $Y_{t}=\theta_{t} K_{t}^{\varepsilon_{f}} N_{t}^{1-\varepsilon_{f}}$, the rate of multifactor productivity growth is the growth rate of $\theta_{t}$. This production function can be rewritten as $Y_{t}=K_{t}^{\varepsilon_{f}}\left(A_{t} N_{t}\right)^{1-\varepsilon_{f}}$ where $A_{t} \equiv \theta_{t}^{\frac{1}{1-\varepsilon_{f}}}$. Thus, the growth rate of $A_{t}$ equals $\frac{1}{1-\varepsilon_{f}}$ times the growth rate of $\theta_{t}$. 
the period 1948-1998, the population of the United States grew at the rate of $1.2 \%$ per year. However, this period included the baby boom. Instead of using data from the baby boom to calibrate the population growth rate, I use the Census Bureau's middle population projection over the entire 21st century to calculate a projected growth rate of $0.7 \%$ per year. ${ }^{22}$ Therefore, I set $G_{N}=(1.007)^{30}$.

I assume that the benchmark functions are symmetric in the sense that $\theta_{y}=\theta_{o}$, and I present results for three values of $\eta$ and for three values of $\theta_{y}=\theta_{o}$, and the implied values of $\varepsilon_{y}$ and $\varepsilon_{o}$, in Table 1 . The row with $\eta=0$ shows the results for the standard model without benchmark levels of consumption. The column with $\theta_{y}=\theta_{o}=0$ (which implies $\varepsilon_{y}=\varepsilon_{o}=0$ ) shows the results under the assumption that a consumer's benchmark level of consumption depends only on the per capita consumption of the consumer's own generation, and is independent of the per capita consumption of the other generation. Since the optimal social marginal product of capital, $f^{\prime}\left(k^{*}\right)$, is independent of $\theta_{y}$ and $\theta_{o}$ (equivalently, it is independent of $\varepsilon_{y}$ and $\varepsilon_{o}$ ), I present the value of $f^{\prime}\left(k^{*}\right)$ once at the beginning of each row, rather

\footnotetext{
${ }^{22}$ The projections were taken from http:// www.census.gov/ population/ projections/
} nation/ summary/ np-t1.txt; Internet Release Date: January 13, 2000, Revised Date: February 14, 2000. 
than repeating the same value in each of the columns of the row. The social marginal product of capital, $f^{\prime}\left(k^{*}\right)$, is the gross rate of return over a 30year period. To help gauge the magnitude of $f^{\prime}\left(k^{*}\right)$, I also the present the annualized gross social marginal product of capital, $f_{a n n}^{\prime} \equiv\left(f^{\prime}\left(k^{*}\right)\right)^{1 / 30}$. For instance, when $\eta=0.25$, the optimal 30-year social gross marginal product of capital, $f^{\prime}\left(k^{*}\right)$, is 7.698 , which implies an annualized gross social marginal product of capital, $f_{a n n}^{\prime}$, of 1.0704 , or equivalently, a net social marginal product of capital, $f_{a n n}^{\prime}-1$, of $7.04 \%$ per year.

Each cell of Table 1 contains three rows, which present the values of the optimal intergenerational consumption ratio, $\sigma^{*}$, the optimal capital income tax rate $\tau_{K}^{*}$, and the optimal lump-sum tax on young consumers, $\tau^{y *}$. To help interpret the tax rate on capital, I will make two adjustments. First, I will annualize the tax rate. Equation (17) implies that the optimal capital income tax rate, $\tau_{K}^{*}$, can be rewritten as $1-\tau_{K}^{*}=\frac{R}{f^{\prime}\left(k^{*}\right)}$, where $R$ and $f^{\prime}\left(k^{*}\right)$ are gross rates of return over a 30-year period. Define $\tau_{K, a n n}^{*}$ as the optimal tax rate on gross capital income, if the capital income tax is levied annually. This annual capital income tax rate satisfies $1-\tau_{K, a n n}^{*}=\frac{R_{a n n}}{f_{a n n}^{\prime}}$ where $R_{a n n} \equiv$ $R^{1 / 30}$ is the annualized gross private rate of return. Therefore, ${ }^{23} \tau_{K, \text { ann }}^{*}=$ ${ }^{23} 1-\tau_{K, a n n}^{*}=\frac{R_{a n n}}{f_{a n n}^{\prime}}=\left(\frac{R}{f^{\prime}\left(k^{*}\right)}\right)^{1 / 30}=\left(1-\tau_{K}^{*}\right)^{1 / 30} . \quad$ Therefore, $\tau_{K, a n n}^{*}=1-$ 
$1-\left(1-\tau_{K}^{*}\right)^{1 / 30}$. The second adjustment converts the tax rate on gross capital income, $f_{a n n}^{\prime}$, to the tax rate on net capital income, $f_{a n n}^{\prime}-1$. Letting $\tau_{K, \text { net }}^{*}$ be the tax rate on annual net capital income ${ }^{24} \tau_{K, \text { net }}^{*}=\frac{f_{a n n}^{\prime}}{f_{a n n}^{\prime}-1} \tau_{K, \text { ann }}^{*}$. Table 1 reports the values of $\tau_{K}^{*}$ and $\tau_{K, n e t}^{*}$. For instance, when $\eta=0.5$ and $\theta_{y} \equiv \theta_{o}=1$, Table 1 shows that $\tau_{K}^{*}=0.043$, which implies that the tax rate on net annual capital income, $\tau_{K, n e t}^{*}$, is 0.027 , or equivalently, $2.7 \%$.

The optimal lump-sum intergenerational tax on young consumers, $\tau^{y *}$, is positive throughout Table 1 , ranging from $2.8 \%$ when $\eta=0.5$ and $\theta_{y}=\theta_{o}=0$ to $7.0 \%$ when $\eta=0$. In the United States, the value of $\tau^{y}$ is about $5 \% .{ }^{25}$ Consistent with Proposition 5, the optimal capital income tax is zero when $\eta=0$ or $\theta_{y}=\theta_{o}=0$. For the cells in Table 1 in which $\eta$ and $\varepsilon^{y}=\varepsilon^{o}$ are positive, $\tau_{K, n e t}^{*}$ is positive but small, with a maximum value of $2.7 \%$ when $\eta=0.5$ and $\theta_{y}=\theta_{o}=1$.

Table 2 presents a simple sensitivity analysis for the values of the annual gross marginal product of capital, $f_{a n n}^{\prime}$, the intergenerational consumption $\left(1-\tau_{K}^{*}\right)^{1 / 30}$.

${ }^{24}$ The net and gross tax rates on annual capital income satisfy $1+$ $\left(1-\tau_{K, n e t}^{*}\right)\left(f_{a n n}^{\prime}-1\right)=\left(1-\tau_{K, a n n}^{*}\right) f_{a n n}^{\prime}$. Therefore, $\tau_{K, \text { net }}^{*}=\tau_{K, a n n}^{*} \frac{f_{a n n}^{\prime}}{f_{a n n}^{\prime}-1}$.

${ }^{25}$ In the United States in 2001, Social Security payroll taxes (OASDI) were $\$ 516.4$ billion and GDP was $\$ 10,082$ billion, so $\tau^{y}$ was equal to 0.051 . 
ratio, $\sigma^{*}$, the tax rate on capital, shown both as the tax rate on the 30 year gross marginal product of capital, $\tau_{K}^{*}$, and the tax rate on the net annual marginal product of capital, $\tau_{K, \text { net }}^{*}$, and the lump-sum intergenerational tax/transfer, $\tau^{y *}$, along a socially optimal balanced growth path. The baseline for this sensitivity analysis uses the parameter values in Table 1 with $\eta=0.5$ and $\theta_{y}=\theta_{o}=1 . \quad$ Each row of the baseline changes one parameter value at a time.

Since $\theta_{y}=\theta_{o}=1$ and $\eta>0$, Corollaries 1 and 3 apply throughout Table 2. Therefore, since $\rho \geq \beta$ throughout Table 2, Corollary 1 implies that $\sigma^{*} \leq 1$, and Corollary 3 implies that $\tau_{K}^{*} \geq 0$. For the two rows in which $\rho=\beta$ (the row with $\rho=(0.98)^{30}$ and the row with $\left.\beta=(0.99)^{30}\right)$, the optimal intergenerational consumption ratio, $\sigma^{*}$, equals one, as implied by Corollary 1 , and the optimal tax rate on capital is zero, as implied by Corollary 3. With the exception of only two rows, Table 2 presents a consistent set of results: the optimal tax rate on net capital income, $\tau_{K, \text { net }}^{*}$, is small ( $5.5 \%$ or less) and the lump-sum tax/transfer system imposes a tax on young consumers and gives a transfer to old consumers. In the two rows that deviate slightly from these results (the row with $\rho=1.00$ and the row with $\alpha=2$ ), the optimal tax rate on net capital income is slightly higher, but still smaller than $10 \%$, 
and the lump-sum tax/transfer system subsidizes young consumers by taxing old consumers (a reverse social security system), but the tax rate is smaller than $3 \%$.

\section{Concluding Remarks}

I have examined the implications for saving and capital accumulation of assuming that consumers care about their consumption relative to a benchmark level of consumption in addition to caring directly about their own consumption. In a competitive economy, individual consumers do not take account of the externality imposed by their consumption, and make their saving and consumption decisions taking as given the consumption of others. With the formulation of utility that I have used here, the introduction of a concern about consumption relative to the benchmark level of consumption is isomorphic to a change in the rate of time preference, from the viewpoint of an individual consumer. Thus, the introduction of concern about the benchmark level of consumption does not dramatically alter the nature of the equilibrium balanced growth path in a competitive economy. However, the characterization of the socially optimal balanced growth path is funda- 
mentally affected by the introduction of a benchmark level of consumption because a social planner internalizes the consumption externality. Taking account of this externality, the socially optimal balanced growth path is characterized by a condition on the intratemporal intergenerational allocation of consumption in addition to the Modified Golden Rule condition, which specifies the optimal capital-labor ratio.

I derived a set of taxes and transfers that induces a competitive economy to attain the socially optimal balanced growth path. This set of taxes consists of a tax on capital income and a lump-sum intergenerational tax/transfer system that resembles pay-as-you-go social security. The optimal set of taxes has a couple of counter-intuitive features. First, though one might be tempted to think that the capital income tax is used to achieve the optimal capital-labor ratio, and the lump-sum intergenerational tax/transfer system is used to attain the optimal intergenerational allocation of consumption, this paper shows that the opposite is the case. If the benchmark level of consumption does not enter the utility, then the Modified Golden Rule capital-labor ratio can be attained by lump-sum intergenerational taxes and transfers that lead to the appropriate level of aggregate saving; the optimal capital income tax rate is zero in this case. However, when the benchmark 
level of consumption enters the utility function, the socially optimal balanced growth path is also characterized by an optimal intergenerational consumption ratio. This value of the intergenerational consumption ratio is attained by the appropriate value of the capital income tax. Indeed, the optimal tax rate on capital income in equation (34) is a function of the intergenerational consumption ratio, but does not depend directly on the capital-labor ratio.

A second counter-intuitive feature of the optimal set of taxes concerns the optimal capital income tax when the social planner is more patient than the individuals. One might be tempted to think that in this case, the social planner would want to foster capital accumulation at a higher rate than in a laissez-faire competitive economy, and thus the optimal tax/transfer system would include a subsidy to capital. However, with benchmarks that are equally-weighted geometric averages of individual consumption $\left(\theta_{y}=\right.$ $\left.\theta_{o}=1\right)$, I derive the opposite result: the optimal capital income tax rate is positive when the social planner is more patient than individuals. In this case, the social planner wants to shift consumption toward future, i.e., younger, consumers. Thus, relative to laissez faire, in each period the social planner wants to shift consumption away from old consumers toward young consumers, and a positive tax on capital income achieves this goal in 
a competitive economy. 


\section{A Competitive Balanced Growth Path}

This appendix characterizes the private rate of return, $R$, and the capitallabor ratio, $k$, along a competitive balanced growth path. Use equation (19) to substitute for $x_{t+1}$ in equation (20), differentiate with respect to $c_{t}$, and set the derivative equal to zero to obtain

$$
\beta M(\sigma) \sigma^{\alpha} G_{A}^{-\eta(1-\alpha)}\left(\frac{x_{t+1}}{c_{t}}\right)^{-\alpha} R_{t+1}=1 .
$$

Use the facts that $c_{t}=C_{t}$ and $x_{t+1}=X_{t+1}$ in equilibrium and that along a balanced growth path $R_{t+1}$ is constant and $X_{t+1}=\sigma G_{A} C_{t}$ to obtain

$$
\beta M(\sigma) G_{A}^{-\alpha-\eta(1-\alpha)} R=1,
$$

which implies equation (23). Also use these facts to rewrite the budget constraint in equation (19) along a balanced growth path as

$$
\sigma G_{A} C_{t}=\left(w_{t}-T_{t}^{y}-C_{t}\right) R-T_{t+1}^{o}+q_{t+1} .
$$

Now use equation (17) to substitute for $R$, equation (15) updated by one period to substitute for $T_{t+1}^{o}$, and equation (18) to substitute for $q_{t+1}$, and recall that $k_{t+1}$ is constant along a balanced growth path to rewrite equation (A.3) as

$$
\sigma G_{A} C_{t}=\left(w_{t}-T_{t}^{y}-C_{t}\right) f^{\prime}(k)+G_{N} T_{t+1}^{y} .
$$


Equation (A.4) is linear in $C_{t}$ and can be easily solved for $C_{t}$ to obtain

$$
C_{t}=\phi\left(w_{t}-T_{t}^{y}+\frac{G_{N} T_{t+1}^{y}}{f^{\prime}(k)}\right)
$$

where

$$
\phi \equiv\left[1+\frac{\sigma G_{A}}{f^{\prime}(k)}\right]^{-1}
$$

The aggregate capital stock at the beginning of period $t+1, K_{t+1}=$ $A_{t+1} N_{t+1} k_{t+1}$, equals the aggregate saving of young consumers during period t. Therefore,

$$
A_{t+1} N_{t+1} k_{t+1}=N_{t}\left(w_{t}-T_{t}^{y}-C_{t}\right)
$$

Use equation (A.5) to substitute for $C_{t}$ in equation (A.7) to obtain

$$
A_{t+1} N_{t+1} k_{t+1}=N_{t}\left((1-\phi)\left(w_{t}-T_{t}^{y}\right)-\phi \frac{G_{N} T_{t+1}^{y}}{f^{\prime}(k)}\right)
$$

Use equation (2) for $w_{t}$, equation (16) for $T_{t}^{y}$, divide both sides of equation (A.8) by $A_{t} N_{t}$, and recall that $k_{t}$ is constant along a balanced growth path to obtain

$$
G_{A} G_{N} k=(1-\phi)\left(f(k)-k f^{\prime}(k)-\frac{T_{0}^{y}}{A_{0}}\right)-\phi \frac{G_{N} G_{A} T_{0}^{y}}{A_{0} f^{\prime}(k)}
$$

Use the definition $\varepsilon_{f} \equiv \frac{k f^{\prime}(k)}{f(k)}$ and rearrange equation (A.9) to obtain

$$
\left[1-\phi+\phi \frac{G_{N} G_{A}}{f^{\prime}(k)}\right] T_{0}^{y}=\left[(1-\phi)\left(1-\varepsilon_{f}\right)-\frac{G_{A} G_{N}}{f^{\prime}(k)} \varepsilon_{f}\right] A_{0} f(k) .
$$




\section{B Optimal Balanced Growth Path}

This appendix derives the values of $\sigma$ and $k$ along the socially optimal balanced growth path. First, rewrite the aggregate resource constraint in equation (4) in terms of $C_{t}$ and $\sigma_{t}$ (rather than in terms of $C_{t}$ and $X_{t}$ ) as

$$
f\left(k_{t}\right)=\left(1+\frac{\sigma_{t}}{G_{N}}\right) \frac{C_{t}}{A_{t}}+G_{A} G_{N} k_{t+1} .
$$

Using equation (26) for the utility of the representative consumer born at the beginning of period $t$, the Lagrangian for the problem of the social planner maximizing the social welfare function in equation (24) subject to the aggregate resource constraint in equation (B.1) is

$$
L=\Sigma_{j=-1}^{\infty} \rho^{j} G_{N}^{j}\left(\begin{array}{c}
\frac{1}{1-\alpha}\left[\left(C_{t+j}^{1-\eta} \sigma_{t+j}^{-\eta \varepsilon_{y}}\right)^{1-\alpha}+\beta\left(C_{t+j+1}^{1-\eta} \sigma_{t+j+1}^{1-\eta+\eta \varepsilon_{o}}\right)^{1-\alpha}\right] \\
+\lambda_{t+j}\left[f\left(k_{t+j}\right)-\left(1+\frac{\sigma_{t+j}}{G_{N}}\right) \frac{C_{t+j}}{A_{t+j}}-G_{N} G_{A} k_{t+j+1}\right]
\end{array}\right) .
$$

Differentiating $L$ with respect to $C_{t+j}, \sigma_{t+j}$, and $k_{t+j+1}$, and setting each derivative equal to zero, yields

$$
\left(\begin{array}{c}
\rho G_{N} \sigma_{t+j}^{-\eta \varepsilon_{y}(1-\alpha)} \\
+\beta \sigma_{t+j}^{\left(1-\eta+\eta \varepsilon_{o}\right)(1-\alpha)}
\end{array}\right)(1-\eta) C_{t+j}^{(1-\eta)(1-\alpha)}=\rho G_{N} \frac{\lambda_{t+j} C_{t+j}}{A_{t+j}}\left(1+\frac{\sigma_{t+j}}{G_{N}}\right)
$$




$$
\left[\begin{array}{c}
-\rho G_{N} \eta \varepsilon_{y} \sigma_{t+j}^{-\eta \varepsilon_{y}(1-\alpha)}+ \\
\left(1-\eta+\eta \varepsilon_{o}\right) \beta \sigma_{t+j}^{\left(1-\eta+\eta \varepsilon_{o}\right)(1-\alpha)}
\end{array}\right] \frac{1}{\sigma_{t+j}} C_{t+j}^{(1-\eta)(1-\alpha)}=\rho \lambda_{t+j} \frac{C_{t+j}}{A_{t+j}}
$$

and

$$
\rho \frac{\lambda_{t+j+1}}{\lambda_{t+j}} f^{\prime}\left(k_{t+j+1}\right)=G_{A}
$$

Now confine attention to balanced growth paths so that $\frac{C_{t+1}}{C_{t}}=\frac{X_{t+1}}{X_{t}}=$ $G_{A}$, and $\sigma_{t}=\sigma$. Evaluate both sides of equation (B.3) along a balanced growth path, multiply both sides by $\sigma^{-\left(1-\eta+\eta \varepsilon_{o}\right)(1-\alpha)}$ and use the definition of $M(\sigma)$ in equation (21) to obtain

$$
(1-\eta)\left[\rho G_{N}[\sigma M(\sigma)]^{-1}+\beta\right] C_{t}^{(1-\eta)(1-\alpha)}=\rho G_{N} \frac{\lambda_{t} C_{t}}{A_{t}}\left(1+\frac{\sigma}{G_{N}}\right) \sigma^{(1-\alpha)\left(-1+\eta-\eta \varepsilon_{o}\right)} .
$$

Equating the gross growth rates of both sides of equation (B.6), and setting $\frac{C_{t+1}}{C_{t}}=G_{A}$ along a balanced growth path, yields

$$
G_{A}^{(1-\eta)(1-\alpha)}=\frac{\lambda_{t+1}}{\lambda_{t}}
$$

Substitute equation (B.7) into equation (B.5), and let $k^{*}$ denote the value of 
$k$ along the optimal balanced growth path, to obtain

$$
\rho f^{\prime}\left(k^{*}\right)=G_{A}^{\alpha+\eta(1-\alpha)} .
$$

Let $\sigma^{*}$ denote the value of $\sigma_{t}$ along the optimal balanced growth path. To determine $\sigma^{*}$, first evaluate equation (B.4) along a balanced growth path and use the definition of $M(\sigma)$ in equation (21) to obtain

$$
\left[\begin{array}{c}
-\rho G_{N} \eta \varepsilon_{y}[\sigma M(\sigma)]^{-1} \\
+\beta\left(1-\eta+\eta \varepsilon_{o}\right)
\end{array}\right] \sigma^{\left(1-\eta+\eta \varepsilon_{o}\right)(1-\alpha)} \frac{1}{\sigma^{*}} C_{t}^{(1-\eta)(1-\alpha)}=\rho \lambda_{t} \frac{C_{t}}{A_{t}} .
$$

Now use equation (B.9) to substitute for $\rho \lambda_{t} \frac{C_{t}}{A_{t}}$ in equation (B.6) and rearrange to obtain

$$
\left[\left(1-\eta+\eta \varepsilon_{y}\right) \frac{\sigma^{*}}{G_{N}}+\eta \varepsilon_{y}\right] \frac{\rho G_{N}}{\beta}\left[\sigma^{*} M\left(\sigma^{*}\right)\right]^{-1}=1-\eta+\eta \varepsilon_{o}+\eta \varepsilon_{o} \frac{\sigma^{*}}{G_{N}} .
$$

Using the definition of $\Psi(r)$ in equation (28), equation (B.10) can be rewritten as

$$
\frac{\rho}{\beta}\left[M\left(\sigma^{*}\right)\right]^{-1}=\Psi\left(\frac{\sigma^{*}}{G_{N}}\right) .
$$

Equation (B.11) implies equation (29) in the text. 


\section{Optimal Intergenerational Tax/Transfer}

This appendix derives the optimal intergenerational transfer in equation (36).

First, rearrange equation (A.6) to obtain

$$
1-\phi=\frac{\sigma G_{A}}{f^{\prime}(k)} \phi
$$

Substitute equation (C.1) into equation (A.10) to obtain

$$
\left(1+\frac{G_{N}}{\sigma}\right) T_{0}^{y}=\left(\frac{1-\varepsilon_{f}}{\varepsilon_{f}}-\phi^{-1} \frac{G_{N}}{\sigma}\right) \varepsilon_{f} A_{0} f(k) .
$$

Now substitute the expression for $f^{\prime}\left(k^{*}\right)$ from equation (27) into equation (C.1) and rearrange to obtain an expression for $\phi^{-1}$ along the socially optimal balanced growth path

$$
\phi^{-1}=1+\sigma \rho G_{A}^{(1-\alpha)(1-\eta)} .
$$

Finally, substitute equation (C.3) into equation (C.2) and multiply both sides of the resulting equation by $\sigma^{*}$ to obtain

$$
\left(\sigma^{*}+G_{N}\right) T_{0}^{y}=\left(\sigma^{*} \frac{1-\varepsilon_{f}}{\varepsilon_{f}}-\sigma^{*} \rho G_{N} G_{A}^{(1-\alpha)(1-\eta)}-G_{N}\right) \varepsilon_{f} A_{0} f\left(k^{*}\right) .
$$

Using the definition $\tau^{y *} \equiv \frac{T_{o}^{y}}{A_{0} f(k)}$ and the definition of $\Lambda$ in equation (37), equation (C.4) implies equation (36). 


\section{Proofs of Lemmas 1 and 2 and Proposition}

\section{1}

Proof of Lemma 1: Define $n \equiv \frac{\eta \varepsilon_{y}}{1-\eta} \geq 0$ and $m \equiv \frac{\eta \varepsilon_{o}}{1-\eta} \geq 0$. Use these definitions to rewrite $\Psi(r)$ in equation (28) as $\Psi(r)=\frac{1+m+m r}{(1+n) r+n} r$. (a) Inspection of the expression for $\Psi(r)$ indicates that $\Psi(r)>0$ since $r>$ 0. (b) $\Psi(r)=\frac{1+m+m r}{1+n+\frac{n}{r}}$, so $\Psi^{\prime}(r)=\frac{m}{1+n+\frac{n}{r}}+\frac{1+m+m r}{\left(1+n+\frac{n}{r}\right)^{2}} \frac{n}{r^{2}}$, which, since $r>0$, is positive, if $m>0$ or if $n>0$. (c) Parts (a) and (b) imply that $\varepsilon_{\Psi} \equiv \frac{r \Psi^{\prime}(r)}{\Psi(r)} \geq 0 . \quad \Psi^{\prime}(r)=\frac{1}{r} \Psi(r)+\frac{m}{1+m+m r} \Psi(r)-\frac{1+n}{(1+n) r+n} \Psi(r)=$ $\frac{1}{r} \Psi(r)\left[1-\frac{1+m+n}{(1+m+m r)((1+n) r+n)} r\right]$. Therefore, $\frac{r \Psi^{\prime}(r)}{\Psi(r)}=1-\frac{(1+m+n) r}{(1+m+m r)((1+n) r+n)}<$ 1 since $r>0$. (d) If $\eta \varepsilon_{y}=\eta \varepsilon_{o}=0$, then $m=n=0$, so $\Psi(r)=\frac{1}{r} r=1$. (e) $\Psi\left(\frac{\varepsilon_{y}}{\varepsilon_{o}}\right)=\Psi\left(\frac{n}{m}\right)=\frac{1+m+m \frac{n}{m}}{(1+n) \frac{n}{m}+n} \frac{n}{m}=\frac{1+m+n}{(1+n+m) n} n=1 . \quad$ (f) If $\eta \varepsilon_{o}=0$ and $\eta \varepsilon_{y}>0$, then $m=0$ and $n>0$. Therefore, $\Psi(r)=\frac{r}{r+(1+r) n}<$ 1. (g) If $\eta \varepsilon_{y}=0$ and $\eta \varepsilon_{o}>0$, then $m>0$ and $n=0$. Therefore, $\Psi(r)=1+m(1+r)>1 . \quad$ (h) $\lim _{r \rightarrow 0} \frac{1}{r} \Psi(r)=\lim _{r \rightarrow 0} \frac{1+m+m r}{(1+n) r+n}=\frac{1+m}{n}=$ $\frac{1-\eta+\eta \varepsilon_{o}}{n \varepsilon_{y}}$ if $\eta \varepsilon_{y}>0$ and $\lim _{r \rightarrow 0} \frac{1}{r} \Psi(r)=\infty$ if $\eta \varepsilon_{y}=0 . \quad$ (i) $\lim _{r \rightarrow \infty} \frac{1}{r} \Psi(r)=$ $\lim _{r \rightarrow \infty} \frac{1+m+m r}{(1+n) r+n}=\frac{m}{1+n}=\frac{\eta \varepsilon_{o}}{1-\eta+\eta \varepsilon_{y}}$.

Proof of Lemma 2: The definition of $\varepsilon_{M}$ in equation (22) implies that $\varepsilon_{M}+\varepsilon_{\Psi}=-\left(1-\varepsilon_{\Psi}\right)-(\alpha-1)\left(1-\eta\left(1-\left(\varepsilon_{y}+\varepsilon_{o}\right)\right)\right)$. Part (c) of Lemma 
1 implies that $-\left(1-\varepsilon_{\Psi}\right)<0$. Since $1-\eta\left(1-\left(\varepsilon^{y}+\varepsilon^{o}\right)\right)>0, \varepsilon_{M}+\varepsilon_{\Psi}<0$ if $\alpha \geq 1$.

Proof of Proposition 1 Existence: Case I: $\alpha>1$. Use the definition of $M(\sigma)$ in equation $(21)$ to obtain $M(\sigma) \Psi\left(\frac{\sigma}{G_{N}}\right)=\sigma^{\varepsilon_{M}+1} \frac{1}{G_{N}} \frac{\Psi\left(\sigma / G_{N}\right)}{\sigma / G_{N}}$. Equation (22) implies that $\varepsilon_{M}+1=(1-\alpha)\left(1-\eta\left(1-\varepsilon_{y}-\varepsilon_{o}\right)\right)<0$ for $\alpha>$ 1. Therefore, since (from Lemma 1, part (h)) $\lim _{r \rightarrow 0} \frac{1}{r} \Psi(r)>0, \lim _{\sigma \rightarrow 0} \sigma^{\varepsilon_{M}+1} \frac{1}{G_{N}} \frac{\Psi\left(\sigma / G_{N}\right)}{\sigma / G_{N}}=$ $\infty$. Since $\lim _{r \rightarrow \infty} \frac{1}{r} \Psi(r)$ is finite (from Lemma 1, part (i)), $\lim _{\sigma \rightarrow \infty} \sigma^{\varepsilon_{M}+1} \frac{1}{G_{N}} \frac{\Psi\left(\sigma / G_{N}\right)}{\sigma / G_{N}}=$ 0. Since $M(\sigma) \Psi\left(\frac{\sigma}{G_{N}}\right)$ is continuous in $\sigma$ for $\sigma>0$, and since $\lim _{\sigma \rightarrow 0} M(\sigma) \Psi\left(\frac{\sigma}{G_{N}}\right)=$ $\infty$ and $\lim _{\sigma \rightarrow \infty} M(\sigma) \Psi\left(\frac{\sigma}{G_{N}}\right)=0$, there exists a $\sigma>0$ for which $M(\sigma) \Psi\left(\frac{\sigma}{G_{N}}\right)=$ $\frac{\rho}{\beta}>0$

Case II: $\alpha=1$ and $0<\frac{\eta \varepsilon_{o}}{1-\eta+\eta \varepsilon_{y}}<\frac{\rho}{\beta} G_{N}<\frac{1-\eta+\eta \varepsilon_{o}}{\eta \varepsilon_{y}}$. If $\alpha=1$, then $\varepsilon_{M}=$ -1 , which implies that $M(\sigma) \Psi\left(\frac{\sigma}{G_{N}}\right)=\frac{1}{G_{N}} \frac{\Psi\left(\sigma / G_{N}\right)}{\sigma / G_{N}}$. Part (h) of Lemma 1 implies that $\lim _{\sigma \rightarrow 0} M(\sigma) \Psi\left(\frac{\sigma}{G_{N}}\right) \geq \frac{1}{G_{N}} \frac{1-\eta+\eta \varepsilon_{o}}{\eta \varepsilon_{y}}$ and part (i) of Lemma 1 implies that $\lim _{\sigma \rightarrow \infty} M(\sigma) \Psi\left(\frac{\sigma}{G_{N}}\right)=\frac{1}{G_{N}} \frac{\eta \varepsilon_{o}}{1-\eta+\eta \varepsilon_{y}}$. Since $M(\sigma) \Psi\left(\frac{\sigma}{G_{N}}\right)$ is continuous in $\sigma$, there exists a $\sigma>0$ such that $M(\sigma) \Psi\left(\frac{\sigma}{G_{N}}\right)=\frac{\rho}{\beta}$ for $\frac{1}{G_{N}} \frac{\eta \varepsilon_{o}}{1-\eta+\eta \varepsilon_{y}}<\frac{\rho}{\beta}<\frac{1}{G_{N}} \frac{1-\eta+\eta \varepsilon_{o}}{\eta \varepsilon_{y}}$.

Uniqueness: Lemma 2 implies that $M(\sigma) \Psi\left(\frac{\sigma}{G_{N}}\right)$ is monotonically decreasing in $\sigma$ in Cases I and II. Therefore, there is at most one value of $\sigma$ for which $M(\sigma) \Psi\left(\frac{\sigma}{G_{N}}\right)=\frac{\rho}{\beta}$. 


\section{E Private and Social Marginal Rates of Sub-}

\section{stitution}

The private intertemporal marginal rate of substitution is $\operatorname{MRS}^{P}\left(c_{t}, x_{t+1}\right) \equiv$ $\beta \frac{\partial u_{t+1}^{o} / \partial x_{t+1}}{\partial u_{t}^{y} / \partial c_{t}}$. Differentiate equation (13) with respect to $c_{t}$ and equation (14) with respect to $x_{t+1}$, and evaluate these derivatives using the definition $\sigma_{t+1} \equiv \frac{X_{t+1}}{C_{t+1}}$ and the fact that in equilibrium $c_{t}=C_{t}$ and $x_{t+1}=X_{t+1}$ to obtain

$$
\operatorname{MRS}^{P}\left(c_{t}, x_{t+1}\right)=\beta \frac{C_{t+1}^{(1-\eta)(1-\alpha)-1} \sigma_{t+1}^{-\alpha-\eta\left(1-\varepsilon_{o}\right)(1-\alpha)}}{C_{t}^{(1-\eta)(1-\alpha)-1} \sigma_{t}^{-\eta \varepsilon_{y}(1-\alpha)}} .
$$

Now evaluate $M R S_{t+1}^{P}\left(c_{t}, x_{t+1}\right)$ along a balanced growth path using the facts that $\sigma_{t+1}=\sigma_{t}$ and $C_{t+1}=G_{A} C_{t}$ along a balanced growth path to obtain

$$
\operatorname{MRS}^{P}\left(c_{t}, x_{t+1}\right)=\beta G_{A}^{(1-\eta)(1-\alpha)-1} \sigma^{-\alpha-(1-\alpha) \eta\left(1-\varepsilon_{o}-\varepsilon_{y}\right)} .
$$

Use the definition of $M(\sigma)$ in equation (21) to rewrite $M R S^{P}\left(c_{t}, x_{t+1}\right)$ as

$$
\operatorname{MRS}^{P}\left(c_{t}, x_{t+1}\right)=\beta G_{A}^{-\alpha-\eta(1-\alpha)} M(\sigma)
$$

The social intertemporal marginal rate of substitution is

$$
\operatorname{MRS}^{S}\left(C_{t}, X_{t+1}\right) \equiv \frac{\beta\left(\partial u_{t+1}^{o} / \partial x_{t+1}+\partial u_{t+1}^{o} / \partial X_{t+1}\right)+\rho G_{N} \partial u_{t+1}^{y} / \partial X_{t+1}}{\partial u_{t}^{y} / \partial c_{t}+\partial u_{t}^{y} / \partial C_{t}+\left(\rho G_{N}\right)^{-1} \beta \partial u_{t}^{o} / \partial C_{t}}
$$


Use equations (13) and (14) to calculate the derivatives in equation (E.4), and evaluate these derivatives using the definition $\sigma_{t+1} \equiv \frac{X_{t+1}}{C_{t+1}}$ and the fact that in equilibrium $c_{t}=C_{t}$ and $x_{t+1}=X_{t+1}$ to obtain

$$
\begin{aligned}
& \beta\left(1-\eta+\eta \varepsilon_{o}\right) X_{t+1}^{(1-\eta)(1-\alpha)-1} \sigma_{t+1}^{\eta \varepsilon_{o}(1-\alpha)} \\
& \operatorname{MRS}^{S}\left(C_{t}, X_{t+1}\right)=\frac{-\rho G_{N} \eta \varepsilon_{y} C_{t+1}^{(1-\eta)(1-\alpha)-1} \sigma_{t+1}^{-\eta \varepsilon_{y}(1-\alpha)-1}}{\left(1-\eta+\eta \varepsilon_{y}\right) C_{t}^{(1-\eta)(1-\alpha)-1} \sigma_{t}^{-\eta \varepsilon_{y}(1-\alpha)}} . \\
& -\left(\rho G_{N}\right)^{-1} \beta \eta \varepsilon_{o} X_{t}^{(1-\eta)(1-\alpha)-1} \sigma_{t}^{\eta \varepsilon_{o}(1-\alpha)+1}
\end{aligned}
$$

Now evaluate $M R S^{S}\left(C_{t}, X_{t+1}\right)$ along a balanced growth path using the facts that $\sigma_{t+1}=\sigma_{t}$ and that $C_{t+1}=G_{A} C_{t}$ along a balanced growth path to obtain

$$
\begin{aligned}
\operatorname{MRS}^{S}\left(C_{t}, X_{t+1}\right) & =\beta G_{A}^{(1-\eta)(1-\alpha)-1} \sigma^{(1-\alpha)\left(1-\eta+\eta \varepsilon_{o}+\eta \varepsilon_{y}\right)-1} \\
& \times \frac{1-\eta+\eta \varepsilon_{o}-\beta^{-1} \rho G_{N} \eta \varepsilon_{y} \sigma^{-(1-\alpha)\left(1-\eta+\eta \varepsilon_{o}+\eta \varepsilon_{y}\right)}}{1-\eta+\eta \varepsilon_{y}-\beta\left(\rho G_{N}\right)^{-1} \eta \varepsilon_{o} \sigma^{(1-\alpha)\left(1-\eta+\eta \varepsilon_{o}+\eta \varepsilon_{y}\right)}} .
\end{aligned}
$$

Now use the expression for $M R S^{P}\left(c_{t}, x_{t+1}\right)$ in equation (E.2) and the definition of $M(\sigma)$ in equation (21) to rewrite equation (E.6) as

$$
\operatorname{MRS}^{S}\left(C_{t}, X_{t+1}\right)=\operatorname{MRS}^{P}\left(c_{t}, x_{t+1}\right) \frac{1-\eta+\eta \varepsilon_{o}-\eta \varepsilon_{y} \rho G_{N} \beta^{-1}[\sigma M(\sigma)]^{-1}}{1-\eta+\eta \varepsilon_{y}-\eta \varepsilon_{o}\left(\rho G_{N}\right)^{-1} \beta \sigma M(\sigma)} .
$$

Define $r^{*} \equiv \frac{\sigma^{*}}{G_{N}}$ and use equation (B.11) to substitute $\frac{\Psi\left(r^{*}\right)}{r^{*}}$ for $\rho G_{N} \beta^{-1}[\sigma M(\sigma)]^{-1}$ 
along a socially optimal balanced growth path in equation (E.7) to obtain

$$
M R S^{S}\left(C_{t}, X_{t+1}\right)=\operatorname{MRS} S^{P}\left(c_{t}, x_{t+1}\right) \frac{1-\eta+\eta \varepsilon_{o}-\eta \varepsilon_{y} \frac{\Psi\left(r^{*}\right)}{r^{*}}}{1-\eta+\eta \varepsilon_{y}-\eta \varepsilon_{o} \frac{r^{*}}{\Psi\left(r^{*}\right)}} .
$$

To simplify the expression on the right hand side of equation (E.8), use the following lemma.

Lemma $5 \frac{1-\eta+\eta \varepsilon_{o}-\eta \varepsilon_{y} \frac{\Psi(r)}{r}}{1-\eta+\eta \varepsilon_{y}-\eta \varepsilon_{o} \frac{r}{\Psi(r)}}=\Psi(r)$.

Proof. Define $n \equiv \frac{\eta \varepsilon_{y}}{1-\eta} \geq 0$ and $m \equiv \frac{\eta \varepsilon_{o}}{1-\eta} \geq 0$ and observe that $\frac{1-\eta+\eta \varepsilon_{o}-\eta \varepsilon_{y} \frac{\Psi(r)}{r}}{1-\eta+\eta \varepsilon_{y}-\eta \varepsilon_{o} \frac{r}{\Psi(r)}}=\frac{1+m-n \frac{\Psi(r)}{r}}{1+n-m \frac{r}{\Psi(r)}}=\frac{1+m-n \frac{\Psi(r)}{r}}{(1+n) \frac{\Psi(r)}{r}-m} \frac{\Psi(r)}{r}=\frac{1+m-n \frac{1+m+m r}{(1+n) r+n}}{(1+n) \frac{1+m+m r}{(1+n) r+n}-m} \frac{\Psi(r)}{r}=\frac{(1+m)(1+n) r-n m r}{(1+n)(1+m)-n m} \frac{\Psi(r)}{r}$ $=\Psi(r)$.

Finally, use Lemma 5 to rewrite equation (E.8) as

$$
M R S^{S}\left(C_{t}, X_{t+1}\right)=M R S^{P}\left(c_{t}, x_{t+1}\right) \times \Psi\left(\frac{\sigma^{*}}{G_{N}}\right) .
$$




\section{References}

[1] Abel, Andrew B., "Asset Prices under Habit Formation and Catching Up with the Joneses," American Economic Review, 80, 2 (May 1990), $38-42$.

[2] Abel, Andrew B., "Risk Premia and Term Premia in General Equilibrium," Journal of Monetary Economics, 43, 1 (February 1999), 3-33.

[3] Blanchard, Olivier J. and Stanley Fischer, Lectures on Macroeconomics, The MIT Press, Cambridge, MA, 1989.

[4] Boskin, Michael J. and Eytan Sheshinski, "Optimal Redistributive Taxation When Individual Welfare Depends upon Relative Income," Quarterly Journal of Economics, 92, 4 (November 1978), 589-601.

[5] Campbell, John Y. and John H. Cochrane, "By Force of Habit: A Consumption-Based Explanation of Aggregate Stock Market Behavior" Journal of Political Economy, 107, 2 (April 1999), 205-51.

[6] de la Croix, David, and Philippe Michel, "Optimal Growth When Tastes Are Inherited," Journal of Economic Dynamics and Control, 23, 4 (February 1999), 519-537. 
[7] Diamond, Peter A., "National Debt in a Neoclassical Growth Model," American Economic Review, 55, 5 (December 1965), 1126-1150.

[8] Duesenberry, James S., Income, Saving and the Theory of Consumer Behavior, Harvard University Press, Cambridge, MA, 1949.

[9] Dupor, Bill and Wen-Fang Liu, "Jealousy and Equilibrium Overconsumption," May 31, 2002, forthcoming in American Economic Review.

[10] Erosa, Andres and Martin Gervais, "Optimal Taxation in Life-Cycle Economies," Journal of Economic Theory, 105, 2 (August 2002), 338369.

[11] Garriga, Carlos, "Optimal Fiscal Policy in Overlapping Generations Models," Working Paper, Department of Economics, Florida State University, January 2001.

[12] Liu, Wen-Fang and Stephen J. Turnovsky, "Consumption Externalities, Production Externalities, and the Accumulation of Capital," University of Washington, Seattle, November 2002. 
[13] Ljungqvist, Lars and Harald Uhlig, "Tax Policy and Aggregate Demand Management Under Catching Up with the Joneses," American Economic Review, 90, 3 (June 2000), 356-366.

[14] Samuelson, "The Two-Part Golden Rule Deduced as the Asymptotic Turnpike of Catenary Motions," Western Economic Journal, 6, 2 (March 1968), 85-89.

[15] United States Census Bureau, Population Estimates Program and Population Projections Program, Population Division, Washington, D.C. 20233, http:// www.census.gov/ population/ projections/ nation/ summary/ np-t1.txt; Internet Release Date: January 13, 2000, Revised Date: February 14, 2000. 


\begin{tabular}{|c|c|c|c|c|c|}
\hline \multicolumn{6}{|c|}{ Socially Optimal Balanced Growth Path } \\
\hline \multicolumn{6}{|c|}{$\begin{array}{c}\varepsilon_{f}=\frac{1}{3}, \alpha=4, \beta=(0.98)^{30}, \rho=(0.99)^{30} \\
G_{A}=(1.018)^{30}, G_{N}=(1.007)^{30}\end{array}$} \\
\hline & & & $\begin{array}{c}\theta_{y}=\theta_{o}=0 \\
\varepsilon_{y}=0 \\
\varepsilon_{o}=0\end{array}$ & $\begin{array}{c}\theta_{y}=\theta_{o}=0.5 \\
\varepsilon_{y}=0.289 \\
\varepsilon_{o}=0.381\end{array}$ & $\begin{array}{l}\theta_{y}=\theta_{o}=1 \\
\varepsilon_{y}=0.448 \\
\varepsilon_{o}=0.552\end{array}$ \\
\hline$\eta=0$ & $\begin{array}{c}f^{\prime}\left(k^{*}\right)=11.499 \\
f_{\text {ann }}^{\prime}=1.0848\end{array}$ & $\begin{array}{c}\sigma^{*} \\
\tau_{K}^{*}, \tau_{K, n e t}^{*} \\
\tau^{y *}\end{array}$ & $\begin{array}{r}0.927 \\
0,0 \\
0.070\end{array}$ & $\begin{array}{l}0.927 \\
0,0 \\
0.070\end{array}$ & $\begin{array}{l}0.927 \\
0,0 \\
0.070\end{array}$ \\
\hline$\eta=0.25$ & $\begin{array}{c}f^{\prime}\left(k^{*}\right)=7.698 \\
f_{a n n}^{\prime}=1.0704\end{array}$ & $\begin{array}{c}\sigma^{*} \\
\tau_{K}^{*}, \tau_{K, n e t}^{*} \\
\tau^{y *}\end{array}$ & $\begin{array}{c}0.911 \\
0,0 \\
0.053\end{array}$ & $\begin{array}{c}0.921 \\
0.002,0.001 \\
0.055\end{array}$ & $\begin{array}{c}0.922 \\
0.020,0.010 \\
0.056\end{array}$ \\
\hline$\eta=0.5$ & $\begin{array}{l}f^{\prime}\left(k^{*}\right)=5.153 \\
f_{\text {ann }}^{\prime}=1.0562\end{array}$ & $\begin{array}{c}\sigma^{*} \\
\tau_{K}^{*}, \tau_{K, n e t}^{*} \\
\tau^{y *}\end{array}$ & $\begin{array}{r}0.885 \\
0,0 \\
0.028\end{array}$ & $\begin{array}{c}0.915 \\
0.008,0.005 \\
0.035\end{array}$ & $\begin{array}{c}0.917 \\
0.043,0.027 \\
0.035\end{array}$ \\
\hline
\end{tabular}

Table 1: Socially Optimal Balanced Growth Path 


\begin{tabular}{|l|c|c|c|c|c|}
\hline \multicolumn{5}{|c|}{ Sensitivity Analysis } \\
\hline Baseline: parameter values in Table 1 with $\eta=0.5$ and $\theta_{y}=\theta_{o}=1$. \\
\hline & $f_{a n n}^{\prime}$ & $\sigma^{*}$ & $\tau_{K}^{*}$ & $\tau_{K, \text { net }}^{*}$ & $\tau^{y^{*}}$ \\
\hline Baseline & 1.0562 & 0.917 & 0.043 & 0.027 & 0.035 \\
\hline$\varepsilon_{f}=0.30$ & 1.0562 & 0.917 & 0.043 & 0.027 & 0.074 \\
\hline$\varepsilon_{f}=0.36$ & 1.0562 & 0.917 & 0.043 & 0.027 & 0.004 \\
\hline$\rho=1.00$ & 1.0456 & 0.841 & 0.084 & 0.067 & -0.002 \\
\hline$\rho=(0.98)^{30}$ & 1.0669 & 1.000 & 0.000 & 0.000 & 0.070 \\
\hline$\beta=(0.99)^{30}$ & 1.0562 & 1.000 & 0.000 & 0.000 & 0.054 \\
\hline$\beta=(0.97)^{30}$ & 1.0562 & 0.839 & 0.084 & 0.055 & 0.017 \\
\hline$N($ years per period) $=25$ & 1.0562 & 0.930 & 0.036 & 0.027 & 0.036 \\
\hline$N($ years per period) $=35$ & 1.0562 & 0.903 & 0.050 & 0.027 & 0.032 \\
\hline$G_{A}=(1.01)^{30}$ & 1.0355 & 0.917 & 0.043 & 0.042 & 0.010 \\
\hline$G_{A}=(1.026)^{30}$ & 1.0770 & 0.917 & 0.043 & 0.020 & 0.052 \\
\hline$G_{N}=1$ & 1.0562 & 0.917 & 0.043 & 0.027 & 0.092 \\
\hline$G_{N}=(1.01)^{30}$ & 1.0562 & 0.917 & 0.043 & 0.027 & 0.011 \\
\hline$\alpha=2$ & 1.0375 & 0.816 & 0.098 & 0.094 & -0.028 \\
\hline$\alpha=6$ & 1.0752 & 0.946 & 0.027 & 0.013 & 0.066 \\
\hline
\end{tabular}

Table 2: SensitivityAnalysis 